SANDIA REPORT SAND81-2581 • Unlimited Release • UC-34

Printed November 1981

g.tकीT

\title{
New Features and Revised Input Instructions for Chart D
}

\author{
J. Michael McGlaun
}

\section{Prepared by}

Sandia National Laboratories

Albuquerque, New Mexico 87185 and Livermore, California 94550

for the United States Department of Energy

under Contract DE-AC04-76DP00789

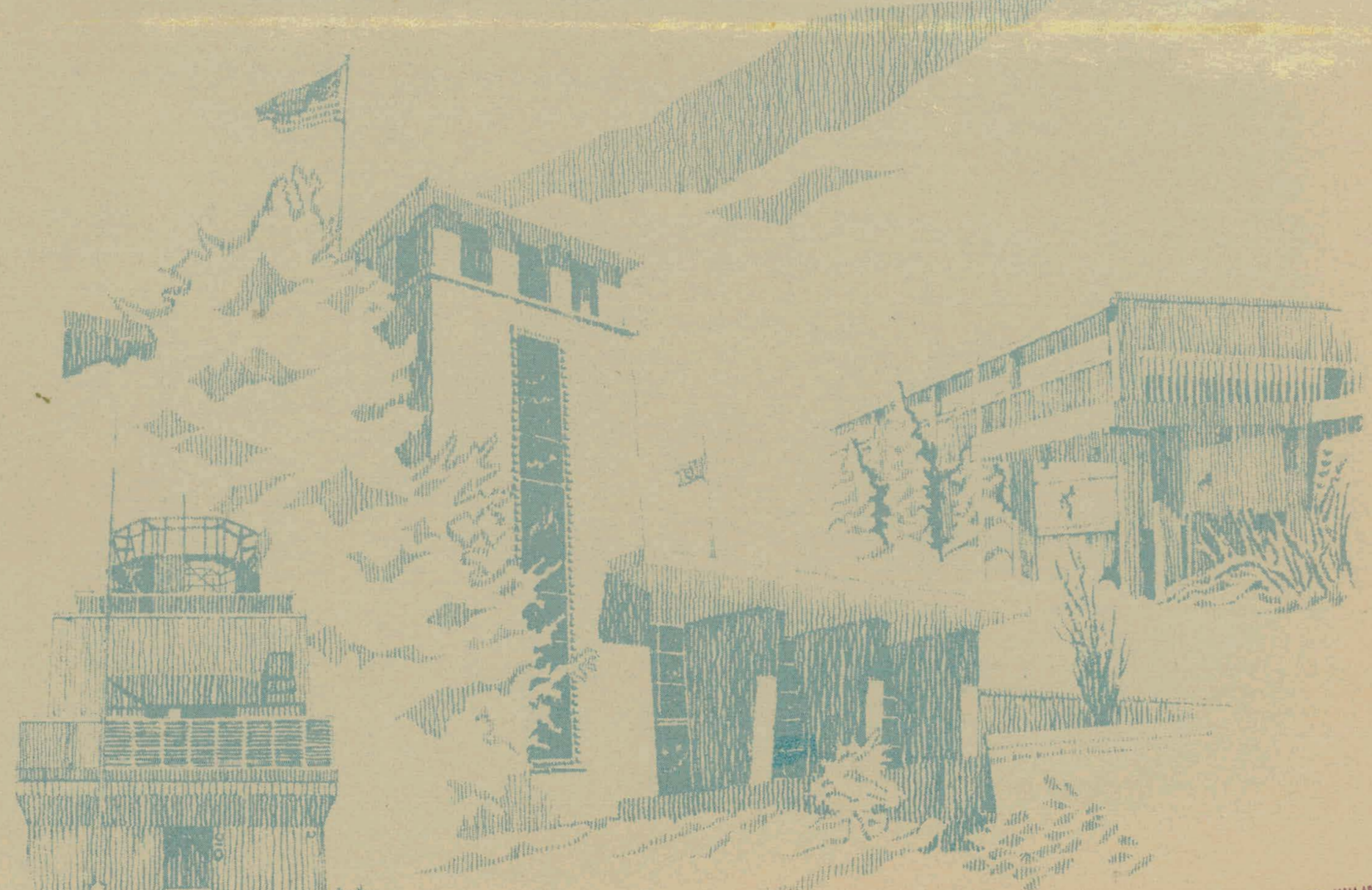




\section{DISCLAIMER}

This report was prepared as an account of work sponsored by an agency of the United States Government. Neither the United States Government nor any agency Thereof, nor any of their employees, makes any warranty, express or implied, or assumes any legal liability or responsibility for the accuracy, completeness, or usefulness of any information, apparatus, product, or process disclosed, or represents that its use would not infringe privately owned rights. Reference herein to any specific commercial product, process, or service by trade name, trademark, manufacturer, or otherwise does not necessarily constitute or imply its endorsement, recommendation, or favoring by the United States Government or any agency thereof. The views and opinions of authors expressed herein do not necessarily state or reflect those of the United States Government or any agency thereof. 


\section{DISCLAIMER}

Portions of this document may be illegible in electronic image products. Images are produced from the best available original document. 
Issued by Sandia National Laboratories, operated for the United States Department of Energy by Sandia Corporation.

NOTICE: This report was prepared as an account of work sponsored by an agency of the United States Government. Neither the United States Governagency of the United States Government. Neither the United States Government nor any agency thereof, nor any of their employees, nor any of their contractors, subcontractors, or their employees, makes any warranty, express
or implied, or assumes any legal liability or responsibility for the accuracy, completeness, or usefulness of any information, apparatus, product, or process disclosed, or represents that its use would not infringe privately owned rights. Reference herein to any specific commercial product, process, or service by trade name, trademark, manufacturer, or otherwise, does not ner necessarily constitute or imply its endorsent by the United States Government, any agency thereof or any of their contractors or subcontractors. The views and opinions expressed herein do not necessarily state or reflect those of the United States Government, any agency thereof or any of their contractors or subcontractors.

Printed in the United States of America Available frum

National Technical Information Servic U.S. Department of Commerce

5285 Port. Rinyal Rnar

Springfield, VA 22161

NTIS price codes

Printed copy: $\$ 8.00$

Microfiche copy: A01 


\section{NOTICE}

PORTHORS OF THIS REPORT ARE ILLEGIBLE.

It has been reproduced from the best ay ailable copy to permit the broadest possible availability.

SAND81-2581

UNLIMITED RELEASE

PRINTED NOVEMBER 1981

NEW FEATURES AND REVISED INPUT INSTRUCTIONS FOR CHART $\frac{D}{2}$

SAND $-81-2581$

DE82 011684

(1)

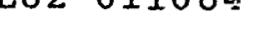


TABLE OF CONTENTS

$\underline{\text { Page }}$

1. Introduction. . . . . . . . . . . . . . 7

2. Edit Frequency Changes Across A Restart . . . . . 9

3. History Edits at Lagrangian Points. . . . . . . 11

4. Generalized Failure Surface . . . . . . . . 13

5. Transmitting Boundary Condition . . . . . . . 17

Appendix A. Revised Chart D Input Instructions . . 19

Appendix B. ANEOS Input Instructions . . . . . . . . 47

Appendix C. MASPLT Input Instructions. . . . . . . 67

References . . . . . . . . . . . . . . . . 77 
LIST OF FIGURES

$\underline{\text { Page }}$

Figure 1. Generalized Failure Surface. . . . . . . 15 


\section{INTRODUCTION}

Chart $\mathrm{D}$ is a one-dimensional, Lagrangian, radiation-hydrodynamics code that has been in use for over ten years. Chart D has changed little in the past few years yet some new features have been added recently that are documented here for the first time. This report describes these new features and the revised input instructions. It does not document features already described in earlier reports $[1,2,3]$.

Four new features have been added to Chart $D$; two improve the editing capability and two improve the physics. The user can now change the print and plot edit frequency when restarting a calculation. The user can also generate history records at Lagrangian locations in the mesh and these records can be processed with the CSQHIST program [4]. These histories can be easily compared to gauge records from experiments. A generalized failure surface has been included which should be better than the von Mises failure surface for modeling geologic materials [5]. A transmitting boundary condition has been added which approximates a semi-infinite material because it absorbs incident stress waves with little reflection. Without a transmitting boundary condition, incident stress waves will reflect off the mesh boundary and propagate back into the mesh. The only alternative to a transmitting boundary condition is to include enough material in the mesh so that reflected stress waves from the boundary do not propagate into the region of interest during the calculation. Each of these four items is discussed in a section 
in the following body of the report. The input for chart $D$, ANEOS, and MASPLT are described in Appendices $A, B$, and $C$. There are no changes in the ANEOS and MASPLT input instractions but they are included in this report for completeness. The Chart $D$ input variables that have been changed are marked with a vertical line to the left of the description of the variable. 


\section{EDIT FREQUENCY CHANGES ACROSS A RESTART}

Binary restart dumps may be written to a file at selected times and at the end of a calculation. Each dump contains all the material data and cell variables at a particular cycle. This data may be read off the file, used to initialize all the variables in Chart $D$, and the calculation may be continued. In the past, the user could not change the print ox plot edit frequency Erom the values written in the restart dump. Recent modifications enable the user to change the'edit frequency when restarting. This can be used to change the edit Erequency during a long calculation. Alternatively, the user can complete the calculation generating a modest number of edits and then return to a time of interest, restart, and generate several print or plot edits during the time of interest. 


\section{HISTORY EDITS AT LAGRANGIAN POINTS}

Chart $D$ has been modified to write binary edit files suitable for input to CSQHIST, the history plot, print, and edit program used by CSQII and TOODY. Cell variables at Lagrangian locations and global quantities associated with material layers can be edited by chart $\mathrm{D}$ and plotted or printed by CSQHIST. For global quantities, the term "layer" in the chart D manual is the same as "material" in the CSQHIST documentation [4]; i.e., layer one in Chart $D$ is material one in CSQHIST.

The format of the edit file from Chart D (unit 55) is exactly the same as the edit file from CSQII. The file is written so that the chart $D$ coordinate $(x)$ is the CSQHIST $x$ coordinate. For cylindrical geometry calculations, $Y$ is the axial coordinate. The Y-velocity and shear stress deviator $\sigma_{\mathrm{xy}}^{\mathrm{d}}$ are zero. The position and velocity of a Lagrangian particle are interpolated from the cell boundary values. In particular, if the position of the particle was initially onefourth the way between the boundaries then the position and velocity are

$$
\begin{aligned}
& \hat{x}=.25 x_{L}+.75 x_{R} \\
& \hat{V}=.25 v_{L}+.75 v_{R}
\end{aligned}
$$

where $\hat{x}(\hat{v})$ is the position (velocity) of a particle, $x_{L}\left(V_{L}\right)$, is the position (velocity) of the left-hand boundary, and $x_{R}\left(V_{R}\right)$ is the position (velocity) of the right-hand boundary. All other edited variables are cell centered values. Cell variables. 
and velocities are written in CGS units but CSQHIST can display the data in a variety of units.

History edits may be requested from any Lagrangian point within a material. An edit cannot be generated for points in an internal void or beyond the external boundaries. Up to one hundred Lagrangian points may be included in a calculation. New points may be added or the location of an existing point may be reilefined at the restart of a calculation. When inserting history points at a restart (cycle > 0), note that the location Df the Lagrangian point is the position in the current mesh, not the initial mesh. The user is warned that the edit file (unit 55) can become very large if there are many Lagrangian points, several layers, or many cycles in a calculation. 


\section{GENERALIZED FAILURE SURFACE}

A generalized failure surface of the following form is available in Chart $D$.

$$
\begin{aligned}
& Y^{2}=\frac{3}{2} \sum_{i}\left(\sigma_{i}^{d}\right)^{2}=\{A-B \exp (C P)\}^{2}\{F(E)\}^{2}, \quad P \geq 0 \\
& Y=Y_{O} F(E), P<0
\end{aligned}
$$

where $\sigma^{\vec{d}}$ is the leviatoric stress tensor, $F(E)$ is described below, and $\mathrm{P}$ is the pressure (the negative of one third of the trace of the stress tensor). It resembles a Drucker-Prager failure surface at low pressures and a von Mises failure sur... face at high pressures. The failure surface of many geologic materials is better approximated by (4.I) than by a von Mises failure surface [5]. Once failure occurs, the stresses are relaxed back to the failure surface using the same algorithm described in the Chart D manual; i.e., the stress deviators are multiplied by an appropriate number so that (4.1) is satisfied. This flow rule is associated with the von Mises failure surface so this model uses a non-associated flow rule.

The input variables for this model are:

$$
\begin{aligned}
& Y_{\infty} \text { - the value of } Y \text { as } P \rightarrow \infty, F(E)=1, \\
& Y_{0} \text { - the value of } Y \text { at } P=0, F(E)=1, \\
& \mathscr{E}_{\mathrm{M}}-\text { (optional) the absolute melt energy, } \\
& \rho_{0}-\text { (optional) the reference density, } \\
& \nu \text { - reference poisson's ratio, }
\end{aligned}
$$




$$
\begin{aligned}
& \alpha \text { - the fraction of melt energy at which the } \\
& \text { material starts to lose strength (normally } 0.8 \text { ), } \\
& \frac{d Y}{d P} \text { - the derivative of } Y \text { with respect to } P \text { at } P=0 \text {. }
\end{aligned}
$$

The relationship between the input data and the constants in (4.1) is easily shown to be

$$
\begin{aligned}
& Y_{\infty}=A \\
& Y_{O}=A-B \\
& \frac{d Y}{d P}=-B C .
\end{aligned}
$$

The values of $\nu$ and $\rho_{0}$ are used to calculate the stress deviators as described in the Chart D manual [1]. $\mathscr{E}_{\mathrm{m}}$ and a are used to define the degradation of the material strength with increasing temperature,

$$
F(E)=\left\{\begin{array}{cl}
1 & \text { if } E \leq \alpha \mathscr{E}_{\mathrm{m}} \\
\frac{\left(1-E, \mathscr{E}_{\mathrm{m}}\right)}{1-\alpha} & \text { if } \alpha \mathscr{E}_{\mathrm{m}}<F<\mathscr{E}_{\mathrm{m}} \\
0 & \text { if } E \geq \mathscr{E}_{\mathrm{m}}
\end{array}\right.
$$

where $\mathrm{E}$ is the specific internal energy of the material. The influence of $Y_{O^{\prime}}, Y_{\infty}$, and $\frac{\partial Y}{d P}$ is displayed in Figure 1 . Nule that $Y=Y_{0}$ if $P<0$. 


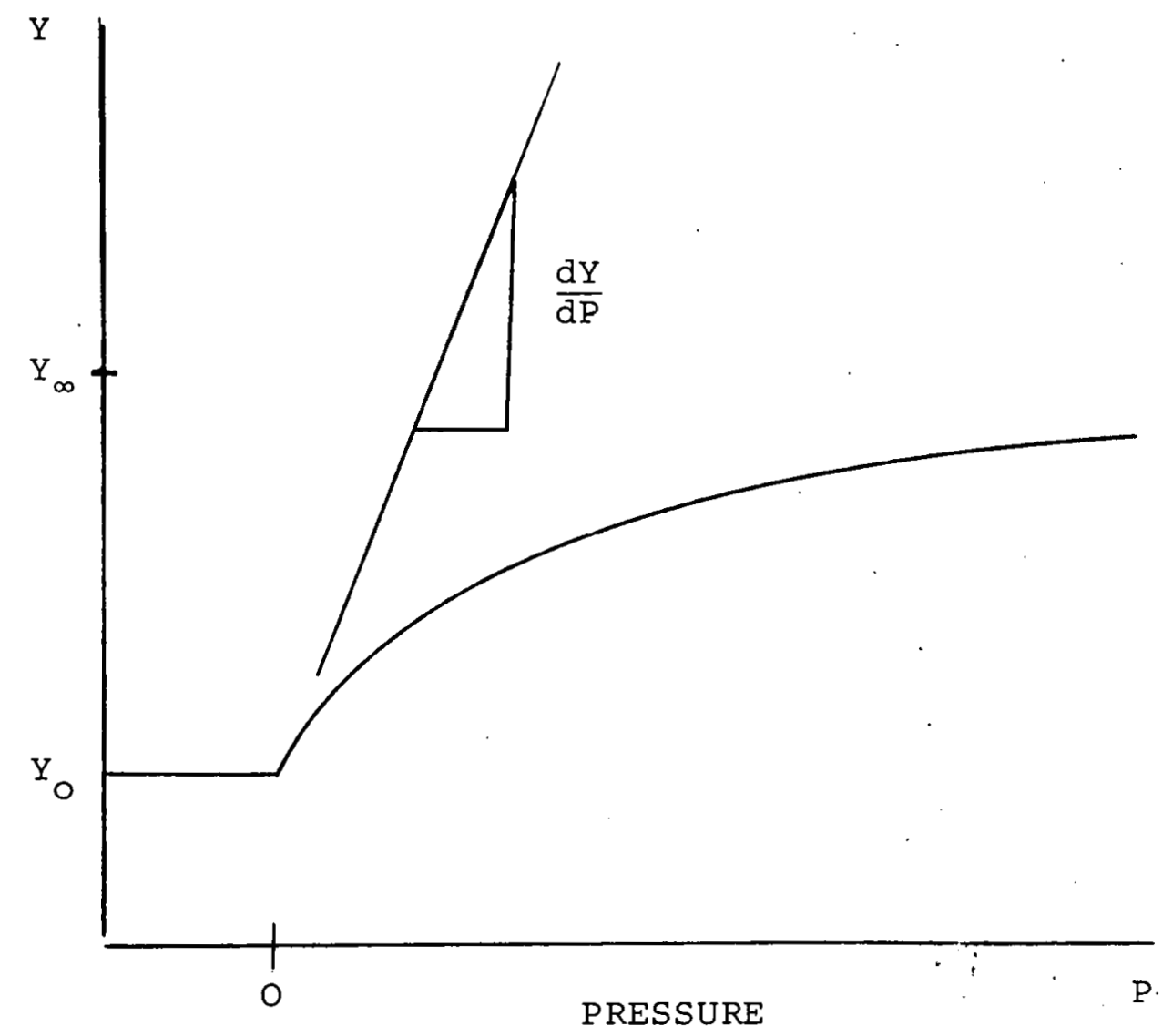

Figure 1. Generalized Failure Surface 
INTENTIONALLY LEFT BLANK 


\section{TRANSMITTING BOUNDARY CONDITION}

Transmitting boundaries simulate semi-infinite homogeneous media in the sense that they absorb incident stress waves with little or no reflection. The only practical alternative to a transmitting boundary is to include enough material in the calculation so that the reflected stress wave from the boundary does not influence the region of interest. This alternative can be very expensive in both CPU time and storage. With transmitting boundaries, only the region of interest need be included in the calculation.

Several types of transmitting boundaries have been developed. The one we use is a generalization of the boundary condition developed by Lysmer and Kuhlemeyer [6] .

$$
\delta \sigma=\rho c \delta u
$$

where $\delta \sigma$ is the increment of the boundary stress, $\rho$ is the mass density, c is the sound speed, and $\delta \mathrm{u}$ is the increment of the houndary velocity. Using this boundary condition and the momentum balance equation, which is also a relationship between velocity and stress, the boundary velocity can be eliminated and a boundary stress calculated. This boundary condition was originally developed for linearly elastic materials so oc was a constant. We have generalized it to nonlinear materials by letting $\rho c$ vary during the calculation. This boundary condition has worked very well on a variety of problems but the user should scrutinize the results. 
INTENTIONALLY IEET BLANK 
APPENDIX A

REVISED CHART: D INPUT INSTRUCTIONS 
2. Optional binary edit output tape for plots. *

3. Binary edit output tape for plots.

7. Standard DTF or BUCKL input tape.

10. Standard restart output tape and input tape.

11. Optional restart output tape.

12. Tabular EOS tape.

$1 \%$ Optional DIF or BUCKL input tape.

55. Material history output tape.

\footnotetext{
"Writing optional binary edit output requires modification of the PROGRAM card. Presently tape units 2 and 3 are equivalenced.
}

The Chart $D$ input variables that have been changed are marked with a vertical line to the left of the description of the variable. 
APPENDIX A

REVISED CHART D INPUT INSTRUCTIONS

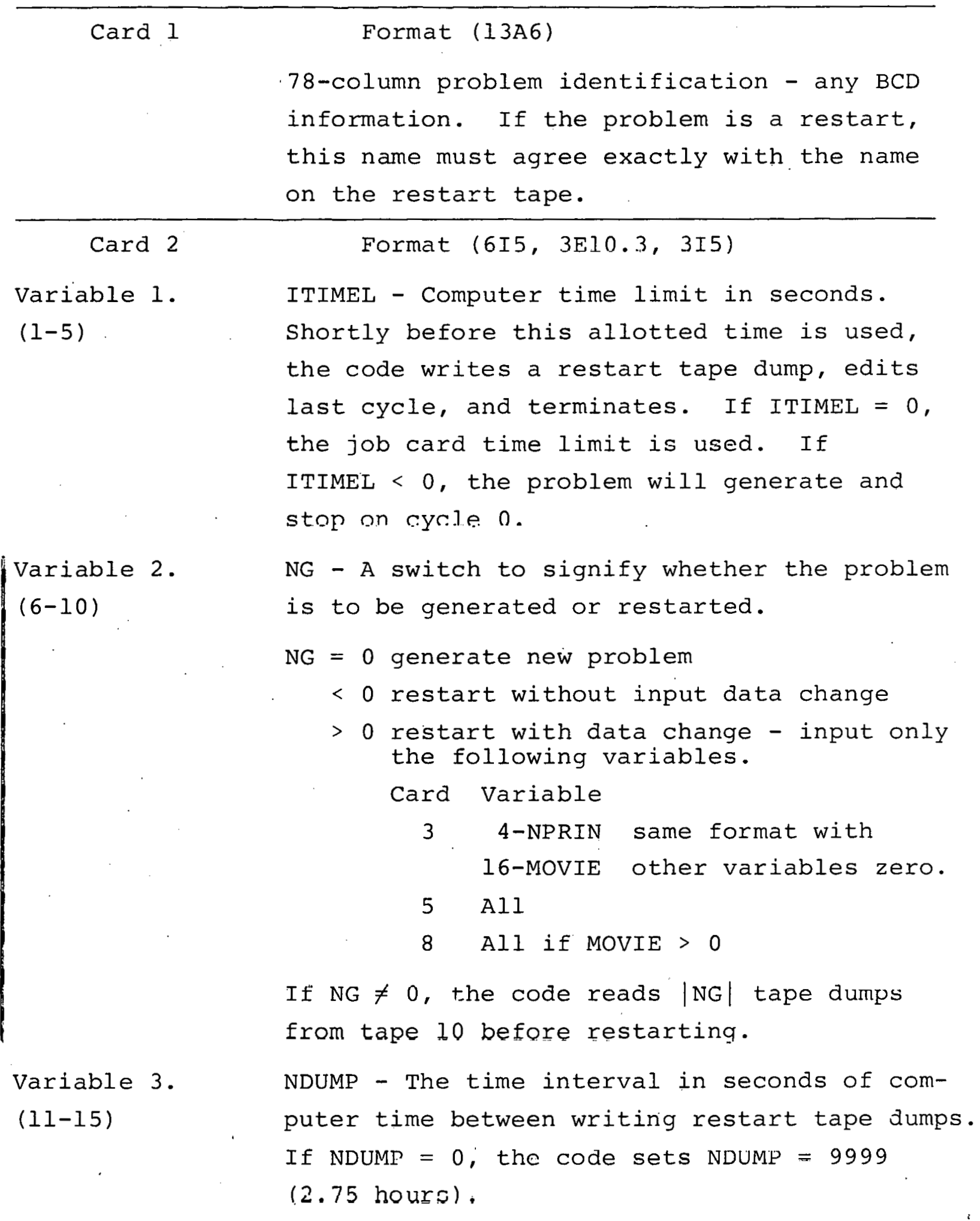


Variable 4 $(16-20)$

Variable 5 . $(21-25)$

Variáble 6 . $(26-30)$

Variable 7 . $(31-40)$

Variable 8 . $(41-50)$

Variable 9. $(51-60)$

Variable 10 . $(6 I-65)$
IS - A switch to select restart output tape. If IS $\leq 0$, restart output on tape 10 (standard). If IS > 0 , restart output on tape 11 (optional). Under the latter option, tape 10 information past the restart point is not destroyed.

ISI - A switch to select extra binary edit output on tape 2. If ISI $\leq 0$, tape 2 edit is not written. If ISI>0, tape 2 edit is written at the same frequency as the print edits. See note on tape units for chart D. NEDREJ - A switch to force edits whenever a fracture or rejoin takes place. If NEDREJ $=u$, no extra edit fulluwiny fracture or rejoin. If NEDREJ > 0 , standard edit following fracture or rejoin. If NEDREJ < 0 , one line edit following fracture or rejoin. PRACDT . Fraction of Courant stability limit used to calculate sound speed time step. (Normally 0.8, in no case greater than 1 ). IE FRACDT $\leq 0$, FRACDT $=0.8$.

DTINCR - Factor used to increase time step from one cycle to the next (normally $\sim 1.05$ ). If DTINCR $\leq 0$, DTINCR $=1.05$.

TEND - The end of problem time. If TEND $\leq 0$, TEND is set to a very large number and the run is terminated on ITIMEL variable.

NEXZON - Indicator for special edit of zone quantities.

If NEXZON $=0$, no special edit.

If $1 \leq \mathrm{NEXZON} \leq$ number of zones, special edit for the $\mathrm{NEXZON}^{\text {th }}$ zone.

If $-100 \leq N E X Z O N \leq-1$, special edit for the rirst zone in the $(-\mathrm{NEXZON})$ th layer. 
If NEXZON < -100, special edit for the last zone in the $(- \text { NEXZON }-100)^{\text {th }}$ layer.

Variable 11. $(66-70)$

$\left\{\begin{array}{l}\text { Variable } 12 . \\ (71-75)\end{array}\right.$
NEXFRE - Cycle frequency of special edits for zone determined by NEXZON.

IHIST - Switch for output on history data tape (unit 55). This data file is for use with CSQHIST plot program.

If $=0$, no nutput to tape 55 .

If $\neq 0$, output data written on tape 55. The frequency of output is every|IHIST: th cycle.

For a new problem generation $($ CYCLE $=0)$ input card set 16 . For a restart (NG $\neq 0$, variable 2), IHIST $>0$ indicates that no additional data is to be entered on card set 16; IHIST < 0 indicates that additional card set 16 data is to be entered.

If this calculation is not a restart, go to card 3. If this calculation is a restart ( $N G \neq 0$ on card 2 ), enter only the information defined by variables 2 and 12 on card 2 (and on cards $3,5,8$ and 16 if appropriate).
Format (16I5)

IGM - A geometry switch.

If $\mathrm{IGM}=1$, plane geometry.

If $\mathrm{IGM}=2$, cylindrical geometry.

If IGM $=3$, spherical geometry.

NRZC - The number of different zoning regions (see card set 11). There is no limit on the size of NRZC.

Variable 3. $(11-15)$
NMTRTS - The number of material layers in the problem. A material layer is a group of cells 
Variable 4 . (16-20)

Variable 5. $(21-25)$

Variable 6. $(26-30)$

Variable 7 . $(31-35)$

Variable 8. $(36-40)$

$\mid \begin{aligned} & \text { Variable } 9 \\ & (41-45) \\ & \text { Variable } 10 \\ & (46-50)\end{aligned}$ that all contain the same material, and has boundary cells that are either at the edge of the mesh or adjacent to cells containing a different material, (see card set ll). NMTRLS $\leq$ NRZC. NMTRLS $\leq 20$. NPRIN - The number of edit (print out) frequency intervals (see card set 5 ).

$1 \leq$ NPRIN $\leq 24$.

NDTMAX - The number of maximum input $\Delta t$ intervals (see card set 6 ). $0 \leq \operatorname{NDTMAX} \leq 24$. If NDTMAX $\leq 0$, the maximum $\Delta t$ is set to $a$ very large number.

NDTMINN - The number of minimum input $\Delta t$ intervals (see card set 7 ). $0 \leq$ NDTMINN $\leq 24$. If NDTMINN $\leq 0$, the minimum $\Delta t$ is zero.

NBPRES - The number of points in the boundary pressure histories (see card set 9). NBPRES $\leq 24$. If NBPRES $\leq 0$, there are no boundary pressures.

NOSOUR - A switch for internal energy sources. If NOSOUR $\leq 0$, there are no internal sources. If NOSOUR > $>$, there are internal sources and NOSOUR is the type of input information (see card set 13). NOSOUR $=1,2,3,4,5$, and 6 are possible.

IBS - A switch to determine if boundary NZP (smallest $X$ ) is transmitting, free to move, or fixed in space. If IBS $=-1$, boundary NZP is transmitting (available only if IGM = I). If IBS $=0$, boundary NZP is free. If IBS $=1$, boundary NZP is fixed $(V \equiv 0)$. OBS - A switch to determine if boundary 1 (largest $X$ ) is transmitting, free to move, or fixed in space. 
Variable 11 . $(51-55)$

Variable 12 . $(56-60)$

Variable 13. $(61-65)$

Variable 14 . $(66-70)$
If $\mathrm{OBS}=-1$, boundary 1 is transmitting. If $\mathrm{OBS}=0$, boundary $I$ is free. If $\mathrm{OBS}=1$, boundary 1 is fixed $(\mathrm{V} \equiv 0)$. NSPALL - A switch for fracture calculations. If NSPALL < 0 , no material fracture is allowed.

If NSPALL $=0$, material fracturing is allowed. If NSPALL > 0 , voids will be zoned into the initial configuration with card set 15. The latter may only be used for plane geometry. If NSPALL < 0 and type 7 zoning (see card set 11) is used, this input is ignored.

NACTION - The number of regions with initially active zones (see card set 14). If NACTION $=0$, only zones with sources or moving boundaries are active on cycle 1 .

NORAD - A radiation switch.

If NORAD $=0$, no radiation diffusion is calculated.

If NORAD $=1$, implicit radiation diffusion. If NORAD $=2$, explicit radiation diffusion. If NORAD $=3$, approximate implicit radiation diffusion.

If NORAD $=4$, the code attempts to use the fastest of $1,2,3$.

The hydrodynamic calculation can be suppressed with options 1 through 4 by using the negative of the option number.

NTHIST - The number of points in the boundary temperatures histories (see card set 10). NTHIST $\leq 24$. (Ignored if NORAD $=0$. ) If NTHIST $\leq 0$, there are no boundary temperatures. 
Variable 15 . $(71-75)$

Variable 16 . $(76-80)$

NRADCK - A switch for the radiation flux

limiter. (Ignored if NORAD $=0$.)

If $\mathrm{NRADCK}=0$, the limiter is used (normal option).

If. NRADCK > 0 , the limiter is not used. If NRADCK $=-1$, the limitcr is used but with $1 / 4$ maximum flux of NRADCK $=0$. (See Section II.4 of [2].)

MOVIE - The number of movie frame frequency intervals. (See card set 8.) MOVIE $\leq 9$. If MOVIE $=0$, no movie tape is produced. If MOVIE > 1, movie tape is produced on unit 3.

Card 4

Variable 1 . $(1-10)$

Variable 2 . $(11-20)$

Variable 3 . $(21-30)$

Variable 4. $(31-40)$

Variable 5 . $(41-50)$
Format (8E10.3)

BI - The constant in the linear viscosity term (normally 0.1). BQ - The constant in the quadratic viscosity term (normally 2.0). Note: Both $B L$ and $B Q$ shouid not be zcro. If $\mathrm{BL}+\mathrm{BQ}=0$, code sets $\mathrm{BL}=0.1$ and $\mathrm{BQ}=2.0$.

XM2(1) - Temporary storage for the fictitious outer boundary mass (boundary l) (normally 0 ). Must be zero if using transmitting boundary. XM2(2) - Temporary storage for the fictitious inner boundary mass (boundary NZP) (normally $0)$. Must be zero if using transmitting boundary.

SCRADF - A scale factor for the front surface boundary temperature. (Ignored if NORAD $=0$.) If $S C R A D F>0$, the incident flux is scaled by SCRADF.

If SCRADF $=0$, the code sets SCRADF $=1$. 
If $\operatorname{SCRADF}<0$, no radiation is allowed to pass through the front surface in either direction, i.e., $\operatorname{FLUX}(1)=0$.

Variable 6 . $(51-60)$

Variable 7 . $(61-70)$

Variable 8 . $(71-80)$
SCRADB - A scale factor for the back surface boundary temperature. Inputs are the same as for Variable 5. (Ignored if NORAD = 0.) Tn cylindrical or spherical geometry, SCRADB is set $=-1$ when there is no central void. If there is a central void, and SCRADB $\geq 0$, any radiation passing into the void.will be lost. SCRADB $<0$ is the physically realistic choice.

TRADOFF - The earliest time at which the code will check to see if the radiation can be turned off (normally 0 ).

SWEP - Elastic-plastic switch.

If $\mathrm{SWEP}=0$, no elastic-plastic calculation.

If SWEP $=1$, elastic-plastic calculation.

\footnotetext{
Card set $5 \quad \begin{aligned} & \text { Format (8EI0.3) Edit (Print out) } \\ & \text { Information }\end{aligned}$

The times refer to problem times in seconds. There are NPRIN sets of these variables (see card 3 ). Variable odd. TIMEP (I) - The time at which edit intervals switch from DTIMEP (I-1) to DTIMEP (I). [TIMEP $(1)=0$, always.]

Variable Even. DTIMEP (I) - The interval between edits from TIMEP (I) to TIMEP $(I+1)$.

For times > TIMEP (NPRIN), the last value of DTIMEP is used to the end of the problem.

Card set $6 \quad \begin{aligned} & \text { Format }(8 E 10.3) \text { Maximum Time step } \\ & \text { Information }\end{aligned}$

Present only if NDTMAX > 0 (see card 3 ).
} 
There are NDTMAX sets of these variables. Variable odd. TTMES (I) - The time at which the maximum time step switches from DLTTMX (I-I) to DLTTMX (I). [TIMES $(1)=0$, always.]

Variable Even. DLTTMX (I) - The maximum time step allowed between TIMES (I) and TIMES $(I+1)$.

For times > TIMES (NDTMAX), the last value of DLTTMX is used to the end of the problem.

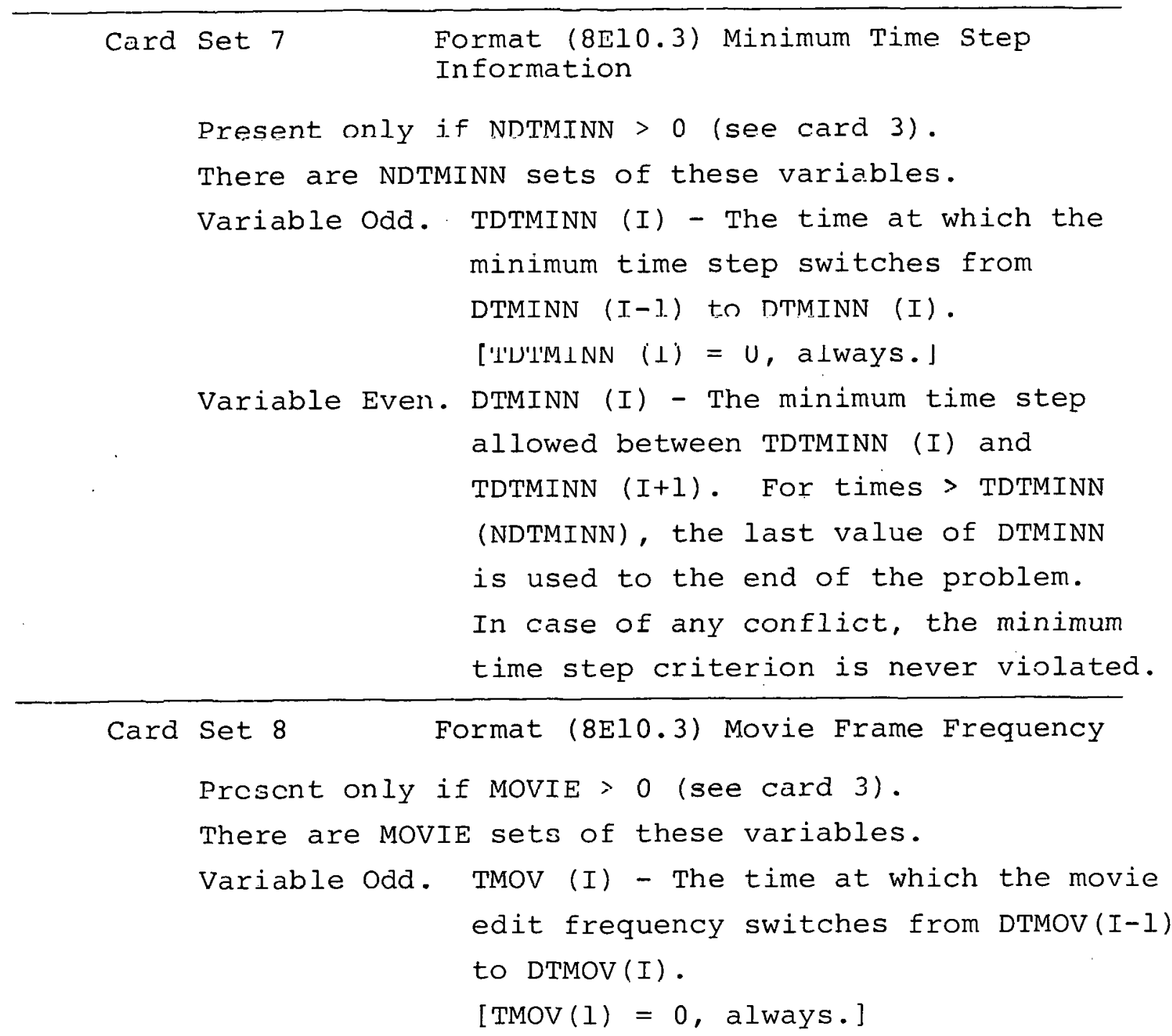


Variable Even. DTMOV(I) - The movie edit frequency time interval from TMOV(I) to $\operatorname{TMOV}(I+1)$.

Note: The dumps are terminated when the time $\geq$ TMOV (MOVIE).

MOVIE $\geq 2$ to function properly.

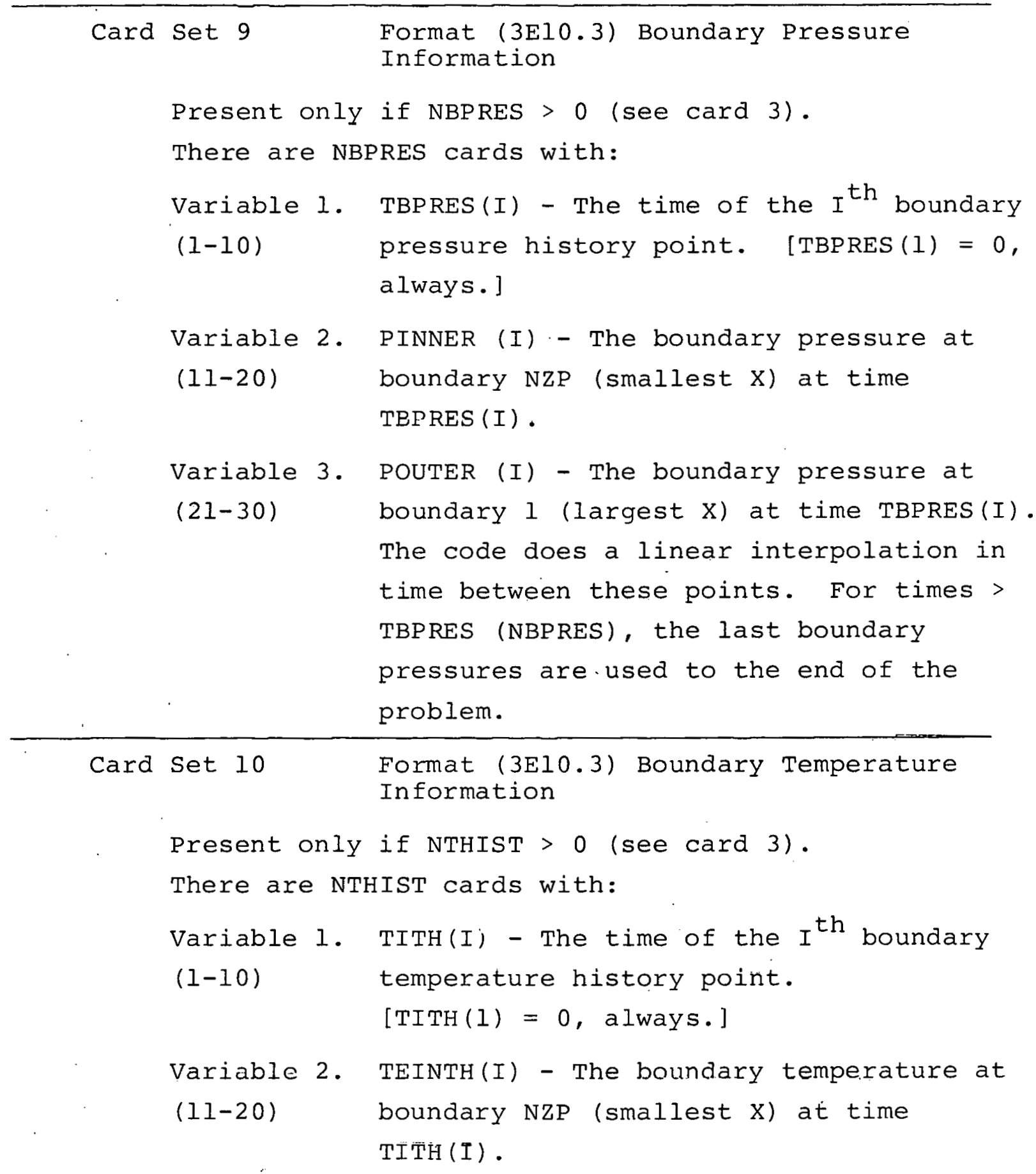


Variable 3. TEOUTH(I) - The boundary temperature at $(21-30)$ boundary 1 (largest $X$ ) at time TITH(I). The code does a linear interpolation in time between these points. For times > TITH (NTHIST), the last boundary temperatures are used to the end of the problem.

Card Set $11 \quad$ Zoning the Problem

The problem is zoned with a series of different regions, each of which is zoned independently. There are NRZC zoning regions and NMTRLS material layers, with NRZC $\geq$ NMTRLS. There can be several regions per material layer but not more than one material in any region. The material boundaries must be a subset of the region boundaries. In a material layer with multiple zoning regions, Chart $D$ uses region information cards 2 and 3 from the last zoning region for all the zoning regions in the material layer. The region information cards for the other zoning regions are read but not used.

Each region is zoned by first giving a set of region information cards and then by using one, and only one, of the seven types of zoning routines. The regions are considered in order, starting with the outermost (largest $\mathrm{X}$ ) and working inward:

Material Boundary Card Format (8El0.3)

Variables. XMATUP (I), $I=1,($ NMTRLS +1$)$. These - are the positions of the boundaries of the various materials, starting with the largest $x$ first. In case Type 7 zoning (voids) is used, the lower boundary of the void is used if the void is between different materials. A void is not counted as a material. Next are NRZC sets of the following cards: 
Region Information Card 1. Format (I5, 5El0.3, I5)

This is always the first card for zoning a region with any of the seven types below.

Variable 1. ITYPE $=90+$ number of the zoning type to be used for this region.

Variable 2 . $x_{u p}$ - The upper boundary (largest $x$ ) of the region $(6-15)$ being zoned. Except for the first region, this must always equal the lower boundary of the preceding region. $x_{u p}$ for the first region is the outer (first) boundary of the problem. For Type 6 zoning in the first region, this is ignored.

Variable 3. $\mathrm{x}_{\text {low }}$ - The lower boundary of the region. For $(16-25)$ the last region this denotes the inner (last) boundary of the problem. For Type 6 zoning in the last region, this is ignored.

Variable 4 . $\rho_{0}$ - The initial density to be used for each $(26-35)$ zone in this region. When Type 1 zoning is used, this density can be superseded for specified zones.

Variable 5. $T_{0}$ - The initial temperature to be used for each (36-45) zone in this region. When Type 1 zoning is used, this temperature can be superseded for specified zones.

If $\mathrm{T}_{\mathrm{O}} \leq 0$, code sets $\mathrm{T}_{\mathrm{O}}=0.02567785\left(298^{\circ} \mathrm{K}\right)$.

Variable 6. $V_{0}$ - The initial velocity to be used for the $(46-55)$ upper boundary of each zone in this region. When Type 1 zoning is used, this velocity can be superseded for specified zones.

Variable 7. IES - The equation-of-state number for the $(56-60)$ material in this region. IES > 0 for tabular EOS. $-20<$ IES < - I for analytic EOS (see card set 12).

For Type 7 zoning, variables 4 to 7 are ignored. 
This is always the second card for zoning a region and contains the information for the elastic-plastic or distended material calculation. The eight input variables are named YIELD(I), $I=1,8$.

Use only one of the following forms.

I. Nonporous - hydrodynamic material or type 7 zoning (void). a blank card

All eight variables read arid stored but not uscd.

TI. Elastic-Plastic von Mises Material (see Section $1 \mathrm{~V}-2$ of [1] and variable 8 , card 4 ).

Variable $1 . \quad Y_{0}$

$(1-10)$

Variable 2. $\mathrm{Y}_{1}$

Variable 3. 0. - Computed internally. The absolute melt (2I 30) energy ( $\left.\mathscr{n}_{m}\right)$ as determined from the equation of state is stored in this location. If a positive number is entered here, it will ovorride the internally computed value.

Variable 4. $\rho_{0}$ - Reference density. If zero, the density $(31-40)$ is taken to be the same as po on region information card 1 .

Variable 5. $\quad v_{0}$ - Reference Poisson's ratio. $(41-50)$

Variable 6 . $\alpha$ - Fraction of melt energy at which the $(51-60)$ material starts to lose strength (normally 0.8 ). If $\alpha \leq 0$, code sets $\alpha=0.8$. 
Variable 7 . 0 .

(61-70)

Variable 8 . 0 .

$(71-80)$

III. Distended or Porous Material (see section V-5 of [1] and Section II.2 of [2]).

Variable 1. $\rho_{\text {so }}$ - Normal solid density at the temperature $(1-10)$ given by $T_{0}$ on region information card 1 . This is used to calculate the initial distention ratio.

Variable:2. $\mathrm{k}_{0}^{\prime}$ - A constant used in computing the tempera$(11-20)$ ture dependence of the crush strength. (See Section II. 2 of [2]). If $\mathrm{k}_{\mathrm{O}}^{\prime}=0$, code sets $\mathrm{k}_{0}^{\prime}=-\cdot 2$.

Variable 3. (-1.) This is a switch. $(21-30)$

Variable 4. $\mathscr{P}_{\mathrm{e}}$ - The elastic limit pressure of the $(31-40)$ material at full distention.

Variable 5. $\quad \mathscr{P}_{S}$ - The elastic limit pressure as all voids $(41-50)$ vanish in the quadratic model, or (-a) - constant in the exponential model.

Variable 6. $C_{\text {eo }}$ - Sound speed in the material at full $(51-60)$ distention. If no value is given, the normal solid sound speed is used.

Variable 7. $\Gamma_{\text {eff }}$ - Effective Grüneisen coefficient for $(61-70)$ revised $\mathrm{P}-\alpha$ model (see Section II.2 of [2]). If $\mathrm{T}_{\text {eff }} \leq 0$, code uses older $\mathrm{P}-\alpha$ model.

Variable 8. $\delta$ - Constant (see section II.2-2 of [2]). $(71-80)$ If $\delta \leq 0$, code sets $\delta=1 / 2$. 
IV. Generalized Failure Surface (see Section 4 and variable 8), card 4)

Variable $1 . \quad Y_{\infty}$

$(1-10)$

Variable 2. $Y_{0}$

$(11-20)$

Variable 3. 0. - Computed internally. The absolute melt

$(21-30)$ energy $\left(\mathscr{E}_{\mathrm{m}}\right)$ as determined from the equation of state is stored in this location. If a positive number is entered here, it will override the internally computed value.

Variable 4. $\rho_{0}$ - Reference density. If zero, the density $(31-40)$

is taken to be the same as po un leyiur information card 1 .

Variable 5. $v_{0}$ - Reference Poisson's ratio.

(41-50)

Variable 6. $\quad \alpha$ - Fraction of melt energy at which the $(51-60)$ material starts to lose strength (normally $0.8)$. If $\alpha \leq 0$, then code sets $\alpha=0.8$.

Variable 7. 0. - Not used. $(61-70)$

Variable 8. $\frac{d Y}{d P}$ - Must be greater than 0 . $(71-80)$ 
Region Information Card $3 \quad$ Format (8E10.3)

This is always the third card for zoning a region and contains the information for the material fracture calculation. The eight input variables are named $F R A C T(I), I=1,8$. Use only one of the four following forms.

I. A blank card for type 7 zoning.

II. Stress Gradient Model (see Section VII of [I] for notation). Variable 1: $\quad \sigma_{\mathrm{u}}$ - Ultimate tensile strength $\left(\sigma_{\mathrm{u}}>0\right)$. $(1-10)$

Variable 2. $\mathrm{T}_{\mathbf{S}}$ - Strength vanishing temperature.

(11-20). If $T_{S} \leq 0$, code sets $T_{S}=10$.

Variable 3. A. $(21-30)$

Variable 4 . B. $(31-40) \quad$ If $B=0$, code sets $B=1$.

Variable 5 . C.

If $C=0$, code sets $C=1$.

Variable 6. $\sigma_{0}$ - Static tensile strength $\left(\sigma_{0}>0\right)$. (51-60) If $\sigma_{0}=0$, code sets $\sigma_{0}=\sigma_{u}$.

Variable 7. Switch to suppress tensions in partially $(61-70)$ melted material.

$=0$, can have tensions above incipient melt.

$=1$, cannot have tensions above incipient melt.

See section (II.3 of [2]).

Variable 8. Scale factor for $Q$ in this layer.

$(71-80)$

Default value is 1 . If negative, the viscosity is used in expansion as well as compression. See Section (II.1 of [2]).

0 or 1 - normal materials

$\sim 4$ or 5 - porous materials

- 1/2 - materials like fused silica 
III. Cumulative Damage Model (see Section VII of [1] for notation).

Variable 1. K(0). (normally 0 ).

$(1-10)$

Variable 2. $\mathrm{T}_{\mathbf{S}}$ - Strength vanishing temperature.

$(11-20)$

If $T_{S} \leq 0$, code sets $T_{S}=10$.

Variable 3. $\sigma_{0}$ - Static tensile strength $\left(\sigma_{0}>0\right)$.

$(21-30)$

Variable 4. $\lambda$.

$(31-40)$

Variable 5. (-C) (must be negative).

$(41-50)$

Variable $6 . \quad \mathrm{K}_{\mathrm{s}}$.

$(51-60)$

$\left.\begin{array}{l}\text { Variable } 7 . \\ (61-70) \\ \text { Variable } 8 . \\ (71-80)\end{array}\right\}$ Same as option II.

IV. Tensile strength Limit (see Section VII of [1] for notation).

Variable $1 . \quad u_{s}-$ Maximum tensile strength $\left(o_{s}>0\right)$.

$(1,-10)$

Variable 2. $\mathbf{T}_{\mathbf{S}}$ - Strength vanishing temperature.

$(11-20)$

If $T_{S} \leq$ code sets $T_{S}=10$.

Variable 3. Blank

$(21-30)$

Variable 4. Blank

$(31-40)$

Variable 5. C.

(41-50) If $C=0$, code sets $C=1$.

Variable 6. Blank

$(51-60)$ 
$\left.\begin{array}{l}\text { Variable } 7 . \\ (61-70) \\ \text { Variable } 8 . \\ (71-80)\end{array}\right\}$ Same as option II.

Seven Zoning Options

Zoning Type $1-\Delta \mathrm{X}$ (HAND) Zoning

First Data Card Format (I5)

Variable 1. NDXC - The number of $\Delta x$ zoning cards used

$(1-5)$ to zone this region.

Next NDXC Data Cards Format (I5, 4E10.3)

Variable 1. The number of zones desired with this $\Delta \mathrm{x}$.

$(1-5)$

Variable 2 .

The $\Delta \mathrm{X}$ to be used for these zones.

$(6-15)$

Variable 3 .

$\rho_{0}^{*}$ - Used as the density for these zones

if $\rho_{0}{ }^{*}>0$; it overrides the specified

region density. If $\rho_{0}{ }^{*}=0$, the specified region density is used.

Variable 4 . $T_{0}^{*}$ - Used as the temperature for these $(26-35)$ zones if $\mathrm{T}_{\mathrm{O}}^{*}>0$; it overrides the specified region temperature. $\perp \pm$ $\mathrm{T}_{\mathrm{O}}^{*}=0$, the specified region temperature is used.

Variable 5. $\quad V_{0}$ * - Used as the velocity of the upper (36-45) boundary for these zones if $\mathrm{V}_{0}{ }^{*} \neq 0$; it overrides the specified region velocity. If $V_{0}^{*}=0$, the specified region velocity is used.

The sum of zone wiaths must equal the difference between the upper and lower region boundaries. 
Zoning Type 2 - Specification of Both Region Boundary Zone Widths (See Appendix B of [1])

only Data Card. : Format (3E10.3)

Variable 1 .

$W_{1}$ - width of first zone in region

(largest $X)$. If $W_{1}<0$, width of first

zone is $-W_{1}$ times the width of last zone

in last region scaled for density. $w_{1}$ cannot be negative for the first region.

Variable 2 . $w_{\ell}$ - Width of last zone in region

$(11-20)$ (Emalloct $\mathrm{Y}$ ).

Variable 3 . Màximum fraction error allowed in ratio $(21-30)$ of adjacent zone masses $(0.01$ is 1 percent).

If the specified input is inconsistent with reality, the zoning will fail.

Zoning Type 3 - Increasing-Decreasing Mass Ratio (suggested only for plane geometry)

only Data Card Format (2E10.3)

Variable 1 .

$W$ - Specifies the width of the first and

last zones of the region. If $W=0$, an error has occurred. If $W>0, W$ is the width of the first and last zones of the region. If $W<0,-W$ times the width of the last zone of the last region is the new zone width for the first and last zones of this region. W cannot be negative in the first region. The zoning routine comes as close to this value as possible.

Variable 2 . RATIO - The ratio of adjacent zone masses $(11-20)$ to be used in the upper (first) half of this region. 1/RATIO is the ratio of adjacent zone masses to be used in the lower (last) half of the region. RATIO may not be 1 . 
If RATIO > 1, this provides thin zones at the region boundaries and thick zones in the region center in order to conserve the number of zones. RATIO < 1 results in thicker zones at the boundaries than at the center. The zone widths are symmetric about the region center.

Zoning Type 4 - Specification of One Region Boundary Zone Width
and Mass Ratio (See Appendix B of [1]) only Data Card Format (4E10.3)

Variable 1. $w_{1}$ - width of first zone in region $(1-10)$ (largest $\mathrm{X}$ ). If $\mathrm{w}_{1}<0$, width of first zone is RATIO times the width of last zone in last region scaled for density. $\mathrm{W}_{1}$ cannot be negative for the first region.

Variable 2 . $W_{\ell}$ - Width of last zone in region $(11-20)$ (smallest $\mathrm{X}$ ).

Variable 3 . RATIO - Adjacent zone mass ratio. $(21-30)$

Variable 4. Maximum fraction error allowed. $(31-40)$

Note: Either $w_{l}$ or $w_{l}$ must be zero and the other variable must be nonzero, RATIO then applies to moving away from the nonzero value.

Zoning Type 5 - Specifications of Mass Ratio and Number of Zones (See Appendix B of [1])

only Data Card Furmal (IJ, El0.3)

Variable 1 . Number of zones desired in region $(>2)$. $(1-5)$

Variable 2 . Mass ratio in increasing position direc(6-15) tion. 
Zoning Type 6 - Free Boundary (only for the first or last region')

Only Data Card Format (I5, 3E10.3)

Variable 1 .

$\ell$ - Number of zones desired in region.

$(1-5)$

Variable 2 .

RATIO - Mass ratio in direction away

$(6-15)$

from interior of problem.

Variable 3 .

$\mathrm{x}_{\mathrm{m}}$ - Maximum or minimum position.

(16-25)

Variable 4 .

Width of interior zone.

$(26-35)$

The region will be zoned away from the interior until

either $\ell$ zones are used or a position of $x_{m}$ is encountered. If $\ell \leq 0, l$ is ignored. If $x_{m}=0, x_{m}$ is ignored. A correction will be made to XMATUP (1) or XMATUP (NMTRLS + I).

Zoning Type 7 - Voids

Used only on interior boundaries and cannot be used when a type 5 energy source is present. There are no data cards.

Cara set 12 - Analytic tquation-oi-state vata

Any inputs for analytic equations of state go here. See Appendix B for format.

Card set 13 - Internal Source Information

Present only if NOSOUR > 0 (see card 3). There are six types of internal sources. However, only one of the six can be used in a given problem. NOSOUR on card 3 determines the type. Type 1 is the hardest to input, but all other types are reduced to Type 1 for code use. See section VIII-4 of [1] for notation. 
Source Type 1 - Hand Input for Each Zone

Card 1

Variable 1 .

$(1-10)$

All Other Cards

Variable 1 .

$(1-5)$

Variable 2 .

$(6-15)$

Variable 3 .

$(16-25)$

Variable 4 .

$(26-35)$

Variable 5 .

$(36-45)$

Variable 6 .

$(46-55)$

Variable 7 .

$(56-65)$
Format (I10)

NOSOUR - The last zone (largest zone

number) in the problem to have a source.

Cards must be ordered by increasing zone number with the smallest number first. The reading is terminated when the zone number $=$ NOSOUR. Zones with number $<$ NOSOUR are not required to have a source and may be omitted from the sequence.

Source Type 2 - Input Total Energy Per Zone

Card $I$ is the same as the first l'ype 1 card.

All Other Data Cards

Variable 1 .

$(1-5)$
Format (I5, 3E10.3)

$I=$ Zone number. 
Variable 2 .

$(6-15)$

Variable 3 .

$(16-25)$

Variable 4 . $(26-35)$

order requirement on zone input is the same as for Type 1.

$$
\dot{\mathscr{P}}_{2}=\dot{\mathscr{P}}_{3}=\frac{\text { zone energy }}{\left(\tau_{4}-\tau_{1}\right) M_{i}}
$$

$\tau_{1}=\tau_{2}$

$\tau_{3}=\tau_{4}$

Zone energy (ergs).

\footnotetext{
Source Type 3 - Input Total Specific Energy Per Zone

Same as Type 2, except Variable 4 is the zone specific energy (ergs/gm).

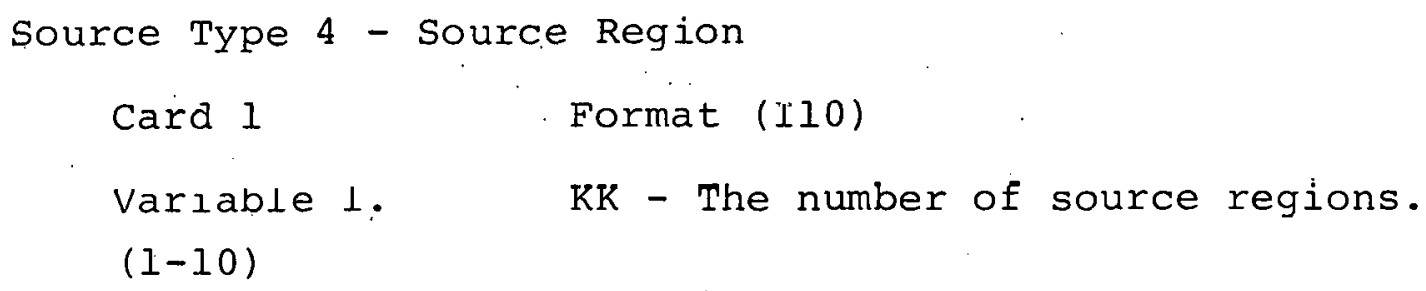

Variable 3 .

Energy source strength, the total energy to be introduced between right and left boundaries.

Variable 4 . $\tau_{1}=\tau_{2}$. $(31-40)$

Variable 5 .

$$
\tau_{3}=\tau_{4} .
$$

(41-50) 
The code will try to match $X$ values with zone boundaries. If it is unable to do this, it will take the right-hand boundary at the first boundary to right of the region and the left-hand boundary at the first boundary to the left. Caution note: On Type 4 when $\mathrm{KK}>1$ : If some regions overlap, the code will lose some of the input energy, since all but the last source in any overlapped zone is dropped. This results in a diagnostic message.

Source Type 5 - Externally Generated Energy Profile (for plane geometry only)

only Input Card Format (6E10.3, 2I5)

Variable 1 .

$F_{0}= \pm \mid$ total incident flux $\mid$.

$(1-10)$

If $F_{0} \geq 0$ flux in ergs $/ \mathrm{cm}^{2}$.

If $\mathrm{F}_{\mathrm{O}}<0$ flux in $\mathrm{cal} / \mathrm{cm}^{2}$.

Variable 2.

$(11-20)$

Variable 3.

$(21-30)$

Variable 4 .

$(31-40)$

Variable 5 .

$(41-50)$

Variable 6 .

$\tau_{1}$

$(51-60)$

Variable 7 .

$(61-65)$

$\tau_{2} \cdot$

$\tau_{3} \cdot$

${ }^{\mathrm{\tau}} 4^{\cdot}$

$\dot{\mathscr{S}}_{2} / \dot{\mathscr{S}}_{3}$ (see Type 1 , same for all zones).

Variable 8.

A switch to select data input tape.

If $\neq 1$, input tape unit is 7 .

If $=1$, input tape unit is $17=$ card reader.

$(66-70)$

A switch for time retardation from front surface.

If $\neq 1$, there is no time retardation.

If $=1$, time retardation is included. 
See section VII-5 of [1]. If card input is indicated, insert cards discussed in Appendix D of [1] at this point. Source Type 6 - HE Burn Format (8E10.3) (See Section X-2 of [1] and section IV.2 of [2])

Variable 1. $(1-10)$

Variable 2 . $(11-20)$

Variable 3 . $(21-30)$

Variable 4 . $(31-40)$

Variable 5 . $(41-50)$

Variable 6 . $(51-60)$

Variable 7. $(61-70)$

Variable 8 . $x_{0}$ - Point of initiation of burn.

$t_{0}$ - Detonation time (start of burn).

$\mathrm{X}_{\mathrm{R}}$ - Right-hand boundary (largest $\mathrm{X}$ ) of burn region.

$x_{L}$ - Left-hand boundary (sma?lest $x$ ) of burn region.

D - Detonation velocity.

Q - Chemical energy release per unit mass. or

$\left(-P_{\text {LJ }}\right)$ - Chapman-Jouguet pressure. The self-detonation calculation is active only if $\mathrm{P}_{\mathrm{CJ}}$ is definea.

$N$ - Number of zonés in the detonation front (normally $\sim 3$ ).

Switch $=1$ if more $\mathrm{HE}$ burn region cards are to to 1 low.

Switch $=0$ if no more cards are to follow.

Card Set 14 - Initial Zone Activation Format (8E10.3)

Present only if NACTION > 0 ( see card 3).

There are NACTION sets of these variables.

Variable odd. Lower boundary of active region.

Variable Even. Upper boundary of active region. 
Card Set 15 - Rezone for Initial Voids with Type 5 Energy Source

Can be used only in plane geometry.

Present only if NSPALL >0 (card 3$)$.

Card 1

Format (I5)

Variable 1 . JJJ - Number of breaks in materials. $(1-5)$

Next JJJ Cards Format (I5, El5.7)

Variable 1 . JJ - The material zone boundary number $(1-5)$ at the break.

Variable 2 . $(6-20)$ The space between the parts of the material.

Initial space can only be made at an interior boundary, i.e., $2 \leq \mathrm{JJ} \leq \mathrm{NMTRLS}$.

Card set 16 - Lagrangian Particle History Edit for CSQHIST Program

Present only if

$$
\begin{aligned}
& \text { 1. CYCLE }=0 \text { (new problem) and IHIST } \neq 0 \\
& \text { 2. CYCLE }>0 \text { (restart) and IHIST }<0
\end{aligned}
$$

There is one of the following cards for each point where it is desired to save the history. Maximum of 100 allowed.

Card Format (Il0, El0.3, Al0)

Variable 1 . NUMB = History particle number. Tf $(1-10)$ input blank or zero, will default to next available number ( 1 for 1st, 2 for 2nd, etc.) NUMB $\leq 100$.

Variable 2 . $X=$ Position in current mesh. If $(11-20)$ CYCLE > 0 (restart) this is not the same as the initial mesh. $x$ must lie 
within a material. It cannot be in an internal void or beyond the external boundaries.

Variable 3 .

$(21-30)$
END FLAG = If this field is blank, the code will continue reading more of these cards: If anything is in the field, no more cards will be read. 
APPENDIX B

ANEOS INPUT INSTRUCTIONS 


\section{APPENDIX B}

\section{ANEOS INFUT INSTRUCTIONS}

The numbers in square brackets [ ] refer to sections or equations in reference 3 unless otherwise stated.

\section{Inputs for ANEOS options 0 to +4}

Card 1

Variable 1 . $(1-3)$

Variable 2 . (4-8)

Variable 3 . $(9-10)$

Variable 4-8. $(11-60)$

Variable 9 . $(61-70)$

Variable 10 . $(71-80)$
Format (I3, I5, I2, 5AI0, 2E10.3)

Equation-of-state number (negative

number). -1 to -20 always.

Library equation-of-state number if desired; otherwise zero.

Used only with a library equation of state. This variable determines the type of analytic calculation (see variable 2, card 2 below). If out of range 0 to 4 , or library information is only for a gas, this input is ignored.

Fifty-column identification label: any $\mathrm{BCD}$ information.

RHUG - The initial density for the Hugoniot calculation. If zero, the calculation is skipped. If negative, the initial density is taken to be the reference density (variable 3 , card 2 below).

THUG - The initial temperature for the Hugoniot calculation. If zero, the calculation is skipped. If negative, the initial temperature is taken to be the

\footnotetext{
* See Appendix C in [3] for contents.
} 
reference temperature (variable 4, card 2 below).

If a library equation of state is requested, no further data cards are required.

Cards 2, 3, and 4

Format (8E10.3)

In the listing, the following variables are called $\mathrm{ZB}(\mathrm{I})$, $I=1,24$.

Variable 1. $(1-10)$

Variable 2 . $(11-20)$

Variable 3 . $(21-30)$

Variable 4. $(31-40)$

Variable 5 . (41-50)
The number of elements in this material.

Switch for type of equation of state. See [3] for these options.

0. - Solid-gas without electronic terms and without detailed treatment of the liquid-vapor region.

1. - Solid-gas with electronic terms but without detailed treatment of the liquid-vapor region.

2. - Gas only with electronic terms.

3. - Same as 0., but with a detailed treatment of the liquid-vapor region.

4. - Same as 1., but with a detailed treatment of the liquid-vapor region.

$\rho_{0}$ - Reference density.

$\mathrm{T}_{\mathrm{O}}$ - Reference temperature.

If $\mathrm{T}_{\mathrm{O}} \leq 0$, code sets $\mathrm{T}_{\mathrm{O}}=0.02567785 \mathrm{ev}$ $\left(298^{\circ} \mathrm{K}\right)$.

$\mathrm{P}_{0}$ - Reference pressure (normally 0 ). 
Variable 6 . $(51-60)$

Variable 7 . $(61-70)$

Variable 8 . $(71-80)$

Variable 9. $(1-10)$

Variable 10. $(11-20)$

Variable 11. $(21-30)$

Variable 12 . $(31-40)$
$B_{O}$ - Reference bulk modulus. (positive number) [III-3],

or

$\left(-S_{0}\right)$ - Constant in linear Hugoniot shockparticle velocity relation (negative number) [VIII-1].

$\Gamma_{0}^{-}-$Reference Grüneisen coefficient.

$1 \theta_{0}$ - Referencc Debye temperature.

If $\theta_{0}=0$, code sets $\theta_{0}=0.025$.

If $\theta_{0}>0$, use high temperature approximation as in [3].

If $\theta_{0}<0$, calculate complete Debye functions. Seee section III-1 of [2].

$\mathrm{T}_{\Gamma}$ - Parameter [3.10].

$\mathrm{T}_{\Gamma}=-1$, slater theory,

$\mathrm{T}_{\Gamma}=" 0$, Dugdalc and MacDonald theory,

$\mathrm{T}_{\Gamma}=1$, free-volume theory,

or

$S_{1}$ - Constant in linear Hugoniot shockparticle velocity relation [VIII-l].

Input variable is defined in relation to variable 6 .

$3 C_{24}$ - Three times the limiting value of the Grüneisen coefficient for large compressions, usually either 2 or 0 . When a value of 2 is used, $C_{24}=2 / 3$ [4.11]. $E_{s}$ - Zero temperature separation energy [3.23].

$\mathrm{T}_{\mathrm{m}}$ - Melting temperature $[\mathrm{V}-5]$, or $\left(-E_{m}\right)$ - Energy to the melting point at zero pressure from the reference point $[\mathrm{V}-5]$. 
Variable 13. (41-50)

Variable 14. $(51-60)$

Variable 15. $(61-70)$

Variable 16. (71-80)

Variable 17. $(1-10)$

Variable 18. (11-20)

Variable 19. (21-30)

Variable 20. (31-40)

Variable 21. (41-50)

Variable 22. (51-60)

Variable 23. $(61-70)$
$\mathrm{C}_{53}$ - Parameter for low density $\mathrm{P}_{C}$ modification to move critical point (normally zero) [3.33] .

$\mathrm{C}_{54}$ - Parameter for low density $\mathrm{P}_{\mathrm{C}}$ modification to move critical point (normally zero) [3.33]:

If $C_{54}=0$ and $C_{53} \neq 0$, codes sets $C_{54}=0.95$.

$\mathrm{H}_{\mathrm{O}}$ - Thermal conductivity coefficient. If zero, thermal conduction is not included. Note that the units of. $\mathrm{H}=\mathrm{H}_{\mathrm{O}}{ }^{\mathrm{T}} \mathrm{C}_{41}$ are ergs $/(\mathrm{cm} \cdot \mathrm{sec} \mathrm{eV})$ [7.6]. $\mathrm{C}_{41}$ - Temperature dependence of thermal conduction coefficient (see variable 15) $[7.6]$.

$\rho_{\text {min }}$ - Lowest allowed solid density, usually about $0.8 \rho_{0}$. If zero or negative, code sets $\rho_{\min }=0.8 \rho_{\circ}[\mathrm{V}-3]$.

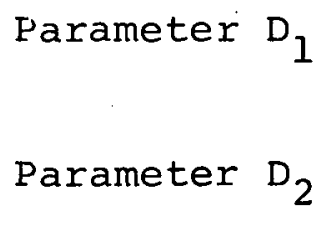

Parameter $\left.\mathrm{D}_{3}\right\}$ Solid-solid phase transition parameters (normally 0$)[\mathrm{V}-7]$.
Parameter $\mathrm{D}_{4}$

Parameter $\mathrm{D}_{5}$

$\mathrm{H}_{\mathrm{f} !}$ - Heat of fusion to determine melt transition parameters [V-I].

If $\mathrm{H}_{f}=0$, no transition is included. 
Lf $\mathrm{H}_{f}<0$, code sets $\mathrm{H}_{\mathrm{f}}=1.117 \times 10^{12}$

$\mathrm{T}_{\mathrm{m}} / \Delta$ (ergs/gm), where $\mathrm{A}$ is the average atomic weight.

Note: Code will run slower if the melt transition is included. Use only when necessary and after testing.

Variable 24 . $\rho_{\ell} / \rho_{s}$ - Ratio of liquid to solid density $(71-80)$ at melt point,

or

$\left(-\rho_{\ell}\right)-$ Density of liquid at melt point, or

$I+\Delta V=1+V_{\ell}-V_{s}-$ Change in volume at melt plus one. Note: In the first option, the input number is between 0 and 1 ; in the second it is negative; and in the third greater than one. If $\mathrm{H}_{\mathrm{f}} \neq 0$ and $\rho_{\ell} / \rho_{s}=0$, code sets $\rho_{\ell} / \rho_{s}=0.95[\mathrm{~V}-1]$.

For a gaseous equation of state (type 2), variables 5 to 14 and 17 to 24 are read but not used.

Card $5 \quad$ Format $(5($ F5.0, E10.3))

There is one set of the following variables for each element in variable 1 , card 2 . $I=1$, number of elements [VI]. Variable odd. - $Z(I)$ - Atomic number of element. Variable Even. Unnormalized atomic number fraction of element. [COT(I)], or

- (Unnormalized atomic weight fraction of element.)

All elements should be defined in the same way. 
Inputs for ANEOS Option-1 (LOW temperature solid)

Card 1

Variable 1 .

Variable 2 .

Variable 3. $(9-10)$

Variable 4-8. $(11-60)$

Variable 9 . $(61-70)$

Variable 10 . $(71-80)$
Format (I3, I5, I2, 5A10, 2E10.3)

Equation-of-state number (negative number). -1 to -20 always.

Library equation-of-state number if desired; otherwise zero.

Used only with a library equation of state. This variable determine the type of analytic calculation (see variable 2, card 2 below). Must be -1 in this case.

Fifty-column identification label: any $B C D$ information.

RHUG = The initial density for the Hugoniot calculation. If zero, the calculation is skipped. If negative, the initial density is taken to be the reference density (variable 3 , card 2 below).

THUG $=$ The initial temperature for the Hugoniot calculation. If zero, the calculation is skipped. If negative, the initial temperature is taken to be the reference temperature (variable 4 , card 2 below).

If a library equation of state is requested, no further data cards are required.

Cards 2,3 , and 4 Format (8E10.3)

In the listing, the following variables are called $\mathrm{ZB}(\mathrm{I})$, $I=1,24$. 
Variable 1. (1-10)

Variable 2 .

(II-20)

Variable 3 . (21-30)

Variable 4 . (31-40)

Variable 5 . $(41-50)$

Variable 6 . $(51-60)$

Variable 7 . (61-70)

Variable 8 . (71-80)

Variable 9. $(1-10)$
The number of elements in this material.

Switch for type of equation of state. Must be -1 for this option.

$\rho_{0}$ - Reference density.

$T_{0}$ - Reference temperature.

If $\mathrm{T}_{\mathrm{O}} \leq 0$, code sets $\mathrm{T}_{\mathrm{O}}=0.02567785 \mathrm{eV}$ $\left(298^{\circ} \mathrm{K}\right)$.

Blank.

$S_{\text {o }}$ - Reference point bulk sound speed.

$\Gamma_{0}-$ Reference Grüneisen coefficient.

Blank.

$s_{1}$ - Constant in linear Hugoniot shockparticle velocity relation for use of (IIT.4.22)

or

(-100) - For power series representation

of $\mathrm{P}_{\mathrm{H}}$ (III.4.23 of [2]). Enter variables 18 to 21 .

or $\left(-s_{1}-100\right)$ - For power series representation with $\mathrm{S}_{1}$ for low density (see Section III.4-1 of (2]).

Variable 10. Blank.

$(11-20)$

Variable 11 .

$\mathrm{C}_{\mathrm{v}}$ - Heat capacity.

$(21-30)$
If $C_{v} \leq 0$, code sets $C_{v}=3 N_{0} k$. 
Variable 12 .

(31-40)

Variable 13.

$(41-50)$

Variable 14.

$(51-60)$.

Variable 15.

(61-70)

Variable 16.

$(71-80)$

Variable 17. $(1-10)$

Variable 18 . $(11-20)$

Variable 19. $(21-30)$

Variable 20 . $(31-40)$

Variable 21. (41-50)

Variable 22 . $(51-60)$

Variable 23. (61-70)

Variable 24. (71-80)
$\mathrm{T}_{\mathrm{m}}$ - Melting temperature or $\left(-E_{m}\right)$ - Energy to the melting point at zero pressure from the reference point (see eq. III.4.34 of [2]).

Blank.

Blank.

$\mathrm{H}_{\mathrm{O}}$ - Thermal conductivity coefficient. If zero, thermal conduction is not included. Note that the units of $\mathrm{H}=\mathrm{H}_{\mathrm{O}} \mathrm{T}^{\mathrm{C}} 41$ are ergs/ $(\mathrm{cm}$ sec eV) [7.6]. $\mathrm{C}_{41}$ - Temperature dependence of thermal conduction coefficient (see variable 15) $[7.6]$.

$\rho_{\text {min }}$ - Lowest allowed solid density, usually about $0.8 \rho_{\circ}$. If zero or negative, code sets $\rho_{\min }=0.8 \rho_{\circ}[\mathrm{V}-3]$.

$\left.\begin{array}{l}\mathrm{K}_{\mathrm{I}} \cdot \\ \mathrm{K}_{2} \cdot \\ \mathrm{K}_{3} \cdot \\ \mathrm{K}_{4} \cdot\end{array}\right\}$

Constants in equation (III.4.23 of [2]). Enter only if variable $9 \leq-100$. Blank otherwise.

Blank.

Blank.

Blank. 


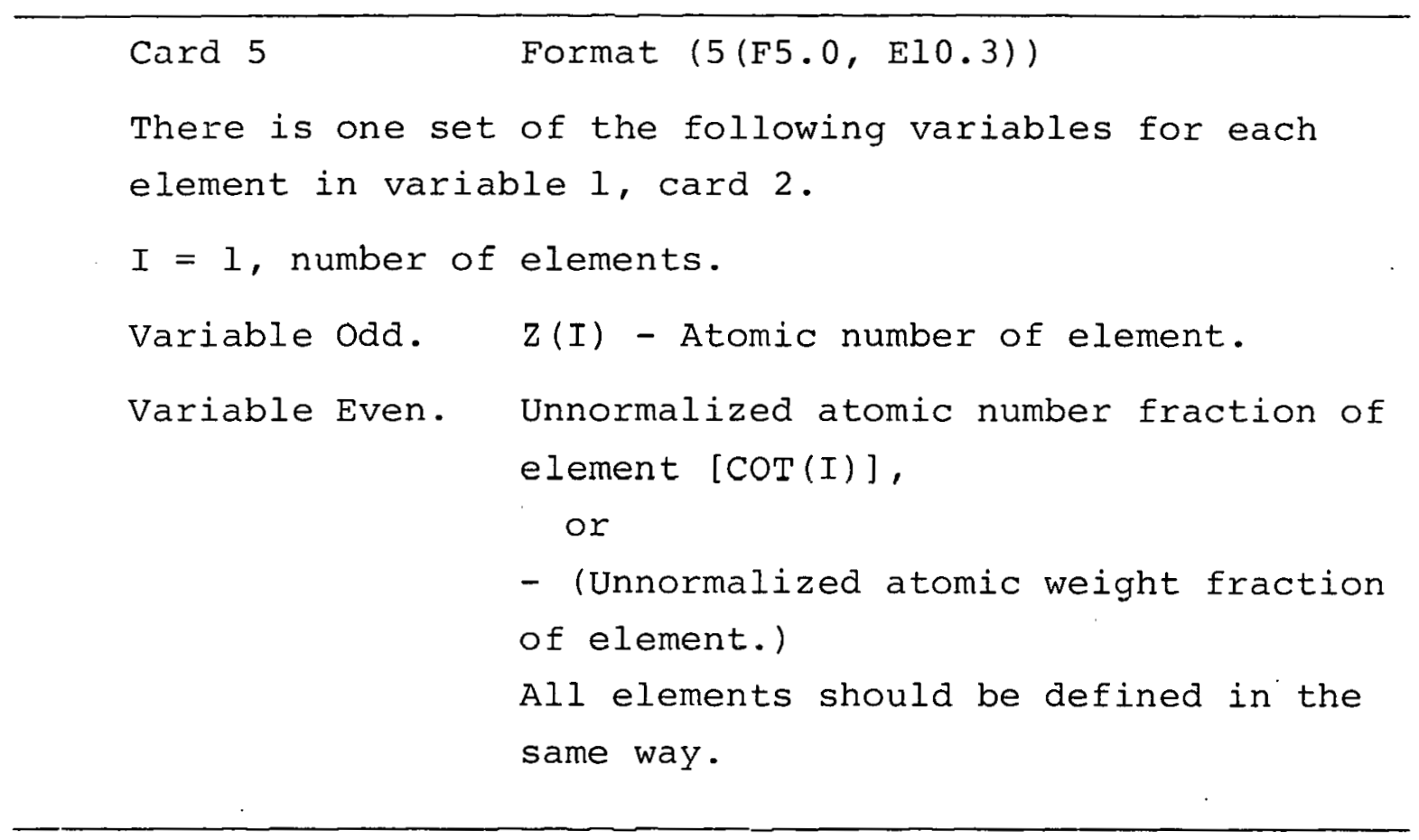


Inputs for ANEOS Option-2 (ideal gas)

Card 1

Variable 1 .

$(1-3)$

Variable 2 .

Variable 3 . $(9-10)$

Variable 4-8. $(11-60)$

Variable 9 . $(61-70)$

Variable 10 . $(71-80)$
Format (I3, I5, I2, 5AI0, 2El0.3)

Equation-of-state number (negative number). -1 to -20 always.

Library equation-of-state number if desired; otherwise zero.

Used only with a library equation of state. This variable determines the type of analytic calculation (see variable 2, card 2 below). Must be -2 in this case.

Fifty-column identification label: any $B C D$ information.

RHUG $=$ The initial density for the Hugoniot calculation. If zero, the calculation is skipped. If negative, the initial density is taken to be the reference density (variable 3 , card 2 below).

THUG = The initial temperature for the Hugoniot calculation. If zero, the calculation is skipped. If negative, the initial temperature is taken to be the reference temperature (variable 4, card 2 below).

If a library equation of state is requested, no further data cards are required.

Cards 2,3 , and 4

Format $(8 E 10.3)$

In the listing, the following variables are called $\mathrm{ZB}$ (I), $I=1,24$. 
Variable 1. $(1-10)$

Variable 2 . (11-20)

Variable 3 . $(21-30)$

Variable 4. (31-40)

Variable 5 . $(41-50)$

Variable 6. $(51=60)$

Variable 7 . $(61-70)$

Variable 8 . $(71-00)$

Variable 9. $(1-10)$

Variable 10. (11-20)

Variable 11. $(21-30)$

Variable 12. $(31-40)$

Variable 13. (41-50)

Variable 14. (51-60)

Variable 15. (61-70)
The number of elements in this material.

Switch for type of equation of state.

Must be -2 for this option.

$\rho_{0}$ - Reference density.

$T_{0}$ - Reference temperature.

If $T_{0} \leq 0$, code sets $T_{0}=0.02567785 \mathrm{eV}$ $\left(298^{\circ} \mathrm{K}\right)$.

$\mathrm{K}_{1}$ - Constant in Rosseland opacity expression. Units are $\mathrm{cm}^{2} / \mathrm{gm}$.

Blank .

$(\gamma-1)$ - Specific heat ratio minus one.

$\mathrm{K}_{2}$ - Constant in Rosseland opacity expression. Units arc cV.

If $\mathrm{K}_{2} \leq 0$, code sets $\mathrm{K}_{2}=.025 \mathrm{eV}$.

Blank.

Blank.

$C_{v}$ - Heat capacity.

If $C_{v} \leq 0$, code sets $C_{v}=3 / 2 N_{o} k$.

Blank.

Blank.

Blank.

Blank. 
Variable 16. Blank.

$(71-80)$

Variable 17. Blank.

$(1-10)$

Variable 18. Blank.

$(11-20)$

Variable 19. Blank.

$(21-30)$

Variable 20. Blank.

(31-40)

Variable 21. Blank.

$(41-50)$

Variable 22. Blank.

$(51-60)$

Variable 23. Blank.

(61-70)

Variable 24. Blank.

$(71-80)$

Card 5 Format $(5($ F5.0, El0.3))

There is one set of the following variables for each

element in variable 1. card 2 .

$I=1$, number of elements.

Variable odd. $\quad \mathrm{Z}(\mathrm{I})$ - Atomic number of element.

Variable Even. Unnormalized atomic number fraction of element [COT (I)」,

or

- (Unnormalized atomic weight fraction of element.)

All elements should be defined in the same way. 
Inputs for ANEOS Option-3 (JWL high explosive)

Card 1

Variable 1 .

$(1-3)$

Variable 2 .

$(4-8)$

Variable 3 . $(9-10)$

Variable 4-8. $(11-60)$

Variable 9. $(61-70)$

Variable 10. $(71-80)$
Format (I3, I5, I2, 5Al0, 2E10.3)

Equation-of-state number (negative number). -1 to -20 always.

Library equation-of-state number if desired; otherwise zero.

Used only with a library equation of state. This variable determines the type nf analytic ralculation (see variable 2, card 2 below). Must be -3 in this case.

Fifty-column identification label: any BCD information.

RHUG = The initial density for the Hugoniot calculation. If zero, the calculation is skipped. If negative, the initial density is taken to be the reference density (variable 3 , card 2 below).

THUG - The initial tompcrature for the Hugoniot calculation. If zero, the calculation is skipped. If negative, the initial temperature is taken to be the reference temperature (variable 4 , card 2 bclow).

If a library equation of state is requested, no further data cards are required.

Cards 2,3 , and 4

Format (8E10.3)

In the listing, the following variables are called $\mathrm{ZB}(\mathrm{I})$, $I=1,24$. 
Variable 1. $(1-10)$

Variable 2 . (II-20)

Variable 3 . $(21-30)$

Variable 4. (31-40)

Variable 5 . (41-50)

Variable 6 . $(5 I-60)$

Variable 7 . $(61-70)$

Variable 8 . (71-80)

Variable 9. $(1-10)$

Variable 10. $(11=20)$

Variable 11. $(21-30)$

Variable 12 . $(31-40)$

Variable 13. (41-50)
The number of elements in this material.

Switch for type of equation of state. Must be -3 for this option.

$\rho_{0}$ - Reference density.

$\mathrm{T}_{\mathrm{O}}$ - Reference temperature.

If $\mathrm{T}_{\mathrm{O}} \leq 0$, code sets $\mathrm{T}_{\mathrm{O}}=0.02567785 \mathrm{eV}$ $\left(298^{\circ} \mathrm{K}\right)$.

$\mathrm{K}_{1}$ - Constant in Rosseland opacity expression. Units are $\mathrm{cm}^{2} / \mathrm{gm}$.

1. - Number which must be entered but not used.

$\omega$ - LLL constant. (See variable 18 below.)

$\mathrm{K}_{2}$ - Constant in Rosseland opacity expression. Units are $\mathrm{eV}$. If $K_{2} \leq 0$, code sets $K_{2}=0.025 \mathrm{eV}$.

Blank.

Blank.

$\mathrm{C}_{\mathrm{v}}$ - Heat capacity.

If $C_{v} \leq 0$, code sets $C_{v}=3 N_{0} k$.

$\mathrm{T}_{\mathrm{m}}$ - Melting temperature. or $\left(-\mathrm{E}_{\mathrm{m}}\right)$ - Energy to the melting point at zero pressure from the reference point (see eq. III.4.34 of [2]).

Blank. 
Variable 14

$(51-60)$

Variable 15 (61-70)

Variable 16. $(71-80)$

Variable 17 . (1-10)

Variable 1.8. (11-20)

Variable 19. $(21-30)$

Variable 20 . (31-40)

Variable 21 . $(41-50)$

Variable 22. (51-60)

Variable 23. (61-7U)

Variable 24. $(71-80)$
Blank.

$\mathrm{H}_{\mathrm{O}}$ - Thermal conductivity coefficient. If zero, thermal conduction is not included. Note that the units of $\mathrm{H}=\mathrm{H}_{\mathrm{O}} \mathrm{T}^{\mathrm{C}} 4 \mathrm{I}$ are ergs $/(\mathrm{cm}$ sec eV) [7.6]. $\mathrm{C}_{41}$ - Temperature dependence of thermal conduction coefficient (see variable 15) $[7.6]$.

$\rho_{\text {min }}$ - Lowest allowed solid density, usually about $0.8 \rho_{0}$. If zero or negative, code sets $\rho_{\min }=0.8 \rho_{0}[\mathrm{~V}-3]$.

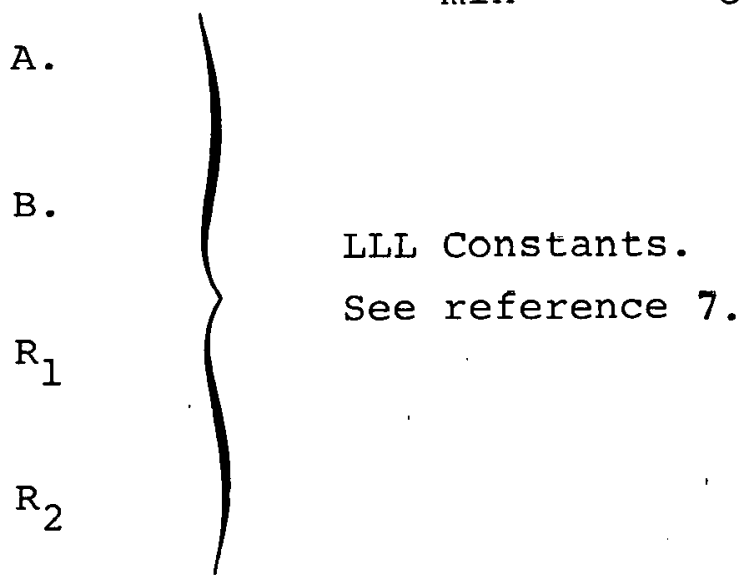

Blank .

Blank.

Blank.

Card 5

Format (5 (F5.0, El0.3))

There is one set of the following variables for each element in variable 1 , card 2 .

$I=1$, number of elements. See reference 7 for element table. 
Variable odd. $\quad Z(I)$ - Atomic number of element.

Variable Even. Unnormalized atomic number fraction of element $[\operatorname{COT}(I)]$,

or

- (Unnormalized atomic weight fraction

of element.)

All elements should be defined in the same way.

Contents of the $C$ Array for EOS Types $-1,-2$ and -3 :

A summary of the contents of the $C$ (internal storage) array for EOS types 0 to 4 is given in Appendix. B of [3]. The following is the corresponding information for the new options. An * next to an equation number means the equation is in reference 3 .

\begin{tabular}{|c|c|c|c|}
\hline & ANEOS -1 & ANEOS -2 & ANEOS - 3 \\
\hline C. & & & $\because \cdots$ \\
\hline 1. & not used & not used & not used \\
\hline 2. & -- & -- & $--\cdots$ \\
\hline 3. & $E_{O}$ & $\gamma$ & $E_{O O}$ \\
\hline 4 & $\mathrm{C}_{\mathrm{V}}$ & $\mathrm{C}_{\mathrm{v}}$ & $\mathrm{C}_{\mathrm{v}}$ \\
\hline 5 & $\rho_{0} \Gamma_{0} C_{v}$ & $(\gamma-1) c_{v}$ & $\mathrm{R}_{1}$ \\
\hline 6. & $\begin{array}{c}\text { error message } \\
\text { counter }\end{array}$ & $\ln \left\{\mathrm{T}_{0} \rho_{0}^{(1-\gamma)}\right\}$ & $\mathrm{R}_{2}$ \\
\hline 7 & -- & -- & -- \\
\hline 8 . & -- & -- & $=-$ \\
\hline 9. & -- & -- & -- \\
\hline 10. & -- & -- & $=-$ \\
\hline 11. & $\rho_{0}$ & $\rho_{0}$ & $\rho_{0}$ \\
\hline 12 & $\mathrm{~T}_{0}$ & $T_{0}$ & $\mathrm{~T}_{\mathrm{O}}$ \\
\hline
\end{tabular}




\begin{tabular}{|c|c|c|}
\hline & ANEOS - 1 & ANEOS - 2 \\
\hline 13. & -- & -- \\
\hline 14. & -- & -- \\
\hline 15. & $\Gamma_{0}$ & $\gamma-1$ \\
\hline 16. & -- & -- \\
\hline 17. & -- & -- \\
\hline 18 & $\mathrm{~T}_{\mathrm{m}}$ & -- \\
\hline 19. & -- & -- \\
\hline 20 & -- & -- \\
\hline 21 & $\rho_{0} S^{2}$ & $\mathrm{~K}_{1} \mathrm{~K}_{2}^{3}$ \\
\hline 22 . & $\begin{array}{c}\text { constant in } \\
(7.8) *\end{array}$ & -- \\
\hline 23 & $\rho_{\text {min }}$ & not used \\
\hline 21. & -- & -- \\
\hline 25. & -- & $\mathrm{K}_{2}$ \\
\hline 26. & ${ }_{1}{ }_{m}[\mathrm{Eq} \cdot(6.5)] *$ & $\mathrm{Z}_{\mathrm{m}}$ \\
\hline 27. & $\mathrm{~N}_{\mathrm{O}}[\mathrm{Eq} \cdot(6.10)] *$ & $\mathrm{~N}_{\mathrm{O}}$ \\
\hline 28 . & $\begin{array}{c}\text { Number of elements } \\
\text { in material. }\end{array}$ & Number of elements \\
\hline 29. & $\overline{\mathrm{A}}[\mathrm{Eq} \cdot(6.2)] *$ & $\overline{\mathrm{A}}$ \\
\hline 30. & $\begin{array}{c}\text { EOS type switch, } \\
-1\end{array}$ & -2 \\
\hline 31. & $\begin{array}{c}\text { Internal storage } \\
\text { location }\end{array}$ & $\begin{array}{c}\text { Internal storage } \\
\text { location }\end{array}$ \\
\hline 32. & $\mathrm{~s}_{\mathrm{O}}$ & -- \\
\hline 33. & $S_{1}$ & -- \\
\hline 34 & . & -- \\
\hline
\end{tabular}




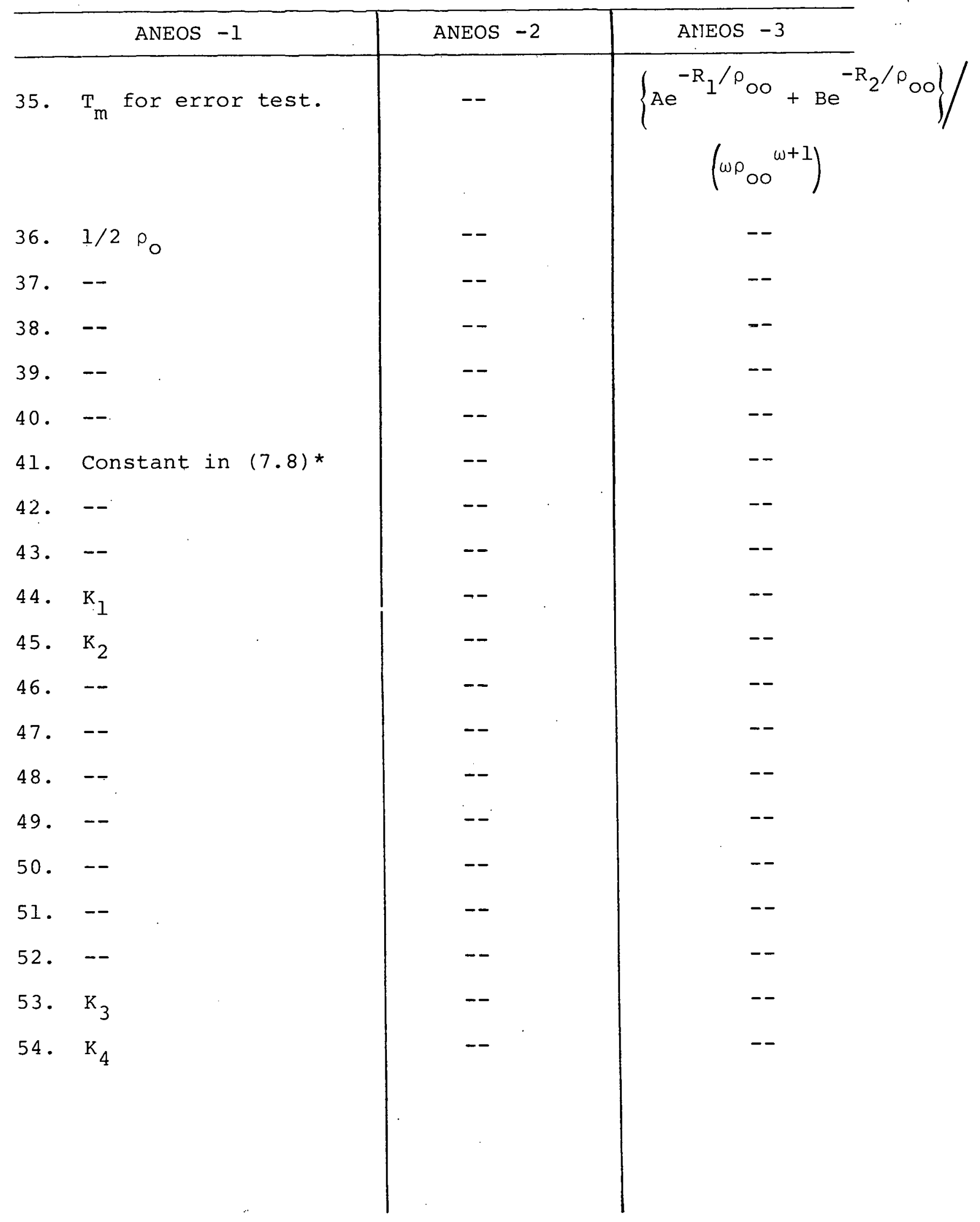


INTENTIONALLY LEFT BLANK 
APPENDIX C

MASPLT INPUT INSTRUCTIONS 
1. Input Tape

2. Input Tape

3. Input Tape

4. Input Tape

39. Output 'l'ape

40. Output Tape 


\section{APPENDIX C \\ MASPLT INPUT INSTRUCTIONS}

\section{MASPLT Input Instructions}

MASPLT is a graphical post-processor for Chart D. It can plot a variety of cell variables and uses the scoRs plotting package.

Table of Variable Selection Code for Parameters 1 and 2 on Card 1 and Card 12

\begin{tabular}{|c|c|c|}
\hline$N(1), N(2)$ & Variable & Standard Unit \\
\hline 1 & $I=$ zone or boundary number & -- \\
\hline 2 & position (boundary) & $\mathrm{cm}$ \\
\hline 3 & position (zone center) & $\mathrm{cm}$ \\
\hline 4 & velocity (boundary) & $\mathrm{cm} / \mathrm{sec}$ \\
\hline 5 & velocity (zone center) & $\mathrm{cm} / \mathrm{sec}$ \\
\hline 6 & temperature & $\mathrm{eV}$ \\
\hline 7 & derisity & $\mathrm{gm} / \mathrm{cc}$ \\
\hline 8 & pressure & dynes $/ \mathrm{cm}^{2}$ \\
\hline 9 & stress $\mathrm{X}$ & dynes $/ \mathrm{cm}^{2}$ \\
\hline 10 & pressure + artificial viscosity & dynes $/ \mathrm{cm}^{2}$ \\
\hline 11 & stress $x+$ artificial viscosity & dynes $/ \mathrm{cm}^{2}$ \\
\hline 12 & $\mathrm{x}$ stress deviator & dynes/cm ${ }^{2}$ \\
\hline 13 & stress $Y$ & dynes $/ \mathrm{cm}^{2}$ \\
\hline 14 & stress $\mathrm{Z}$ & dynes $/ \mathrm{cm}^{2}$ \\
\hline 15 & Z stréss deviator & dynes/cm ${ }^{2}$ \\
\hline 16 & specific entropy & ergs/gm ev \\
\hline 17 & specific internal energy & ergs/gm \\
\hline 18 & distention ratio & -- \\
\hline 19 & momentum summed from front* & taps \\
\hline 20 & mass depth from front* & $g m$ \\
\hline 21 & $\begin{array}{l}\text { solid density (distention } \\
\text { ratio } x \text { density) }\end{array}$ & $\mathrm{gm} / \mathrm{cc}$ \\
\hline
\end{tabular}


Card 1

$(1-5)$

$(6-10)$

$(11-15)$

$(16-20)$

$(21-25)$

$(26-30)$

$(31-35)$

$(36-40)$
Format (16I5)

$\mathrm{N}(1)=\mathrm{X}$ (abscissa) variable code (see Table). Not used if $\mathrm{N}(16)=1$.

$\mathrm{N}(2)=\mathrm{Y}$. (ordinate) variable code (see Table). or

$-1,-2$ for plots with several curves on each frame. Code will attempt to save $Y$ mesh from one frame to the next if -2 , will not save if -1 , Use with $\mathrm{N}(4)=\mathrm{N}(5)=\mathrm{N}(6)=\mathrm{N}(7)=\mathrm{N}(16)=0$. YMIN and YMAX on card 8.1 are not used. Add card 12 data. Not used if $\mathrm{N}(16)=1$.

$N(3)=0$ for output on tape unit 40 .

$=1$ for output on tape unit 39 .

$\mathrm{N}(4)=0$ plot frequency determined by record number.

$=1$ plot frequency determined by time inpuls.

See card set 8 . Not used if $N(16)=1$.

$N(5)=0$ for linear $x$ scale.

$=$ for $\log x$ scale.

$N(6)=0$ for linear $Y$ scale.

$=1$ for $\log \mathrm{Y}$ scale.

$N(7)=0$ no plot grid is shown on graph.

$=1$ plot grid is shown on graph.

$\mathrm{N}(8)$ determines number of title and The End trames.

If $N(8)>0, N(8)$ is the number of frames of each. If $N(8)=0$, no title or The End frames. 
If $-1000 \leq N(8)<0$, no The End frames but $-\mathrm{N}(8)$ title frames. If $N(8)<-1000$, no title frames but $-(N(8)+1000)$ The End frames.

The options with $\mathrm{N}(8) \leq 0$ are useful in making continuous movies from several data tapes.

$(41-45)$

$(46-50)$ $N(10)=$ number of frames of the first plot in a given interval. This is useful in freezing the action in a movie to adjust to scale. changes.

(51-55) $\quad \mathrm{N}(11)=0$. Join points with lines.

$=1$. Do not join points with lines.

$=2$. Join points with lines except across spalls. (2 not available if $N(2)=-1$ or -2 ).

(56-60) $N(12)=0$ for small size frame. This must be used for movies or any $16 \mathrm{~mm}$ plot because of frame overlap.

$=1$ for large size frame. Plot grid is always shown.

$(61-65) \quad \mathrm{N}(13)=$ number of data packages in card 8 . If $N(16)=0$, then $0<N(13) \leq 10$. If $N(16)=1$, then $N(13)=0$.

(66-70) $\mathrm{N}(14)=$ number of plot symbols in card 6 . $1 \leq N(14) \leq 50$.

(71-75) $\quad \mathrm{N}(1.5)=$ input tape number $(1,2,3$, or 4$)$. (76-80) $N(16)=0$ for plot of variables at a given time. $=1$ for a single plot of variable as a function of time or with time as a parameter. User must supply subroutine 
TIMEVA.

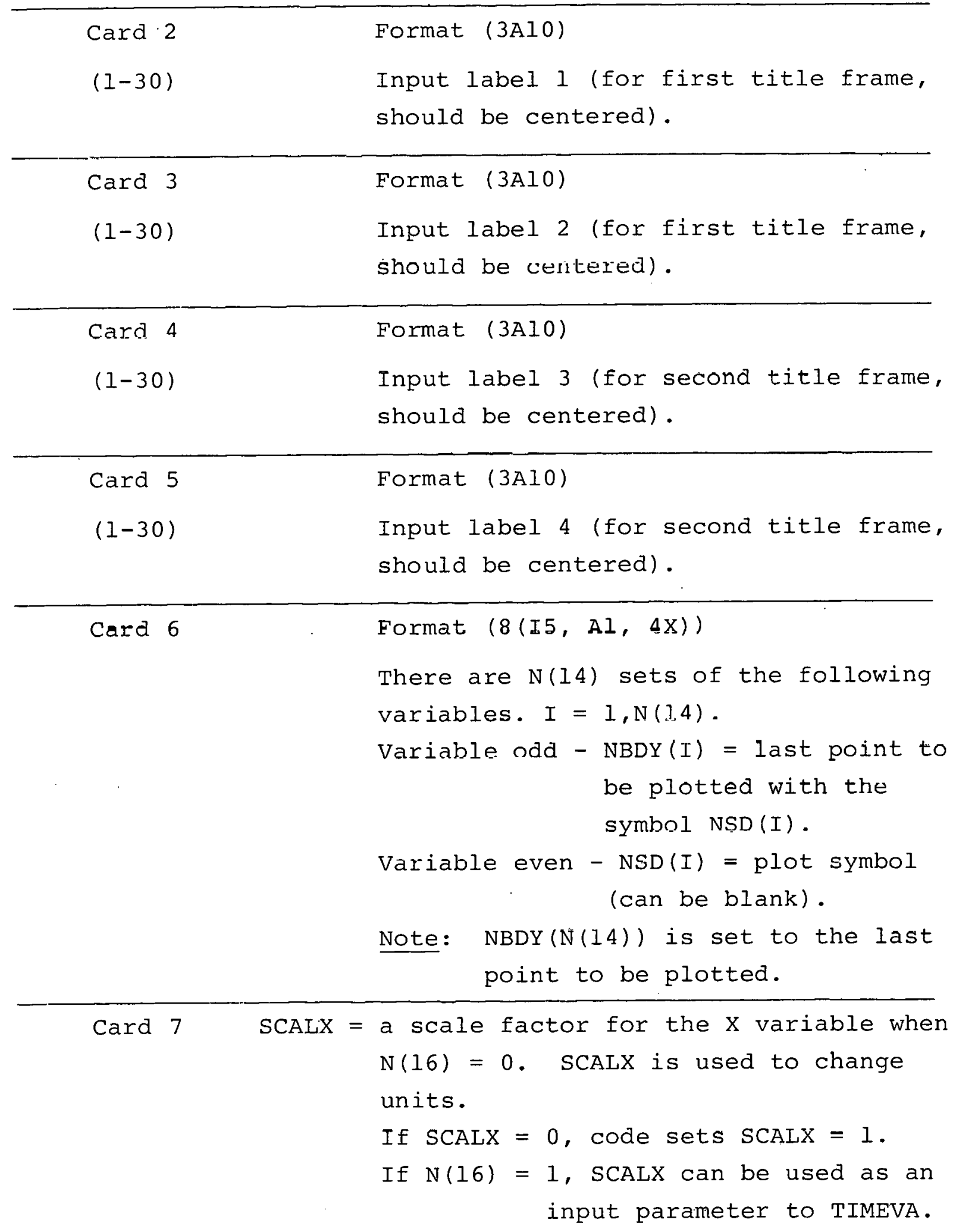


(11-20) SCALY = same as SCALX except for $\mathrm{Y}$ variable.

(21-30) DLABX $=0$ - for MASPLT to supply $x$ label.

$=1$ - input $x$ label in card set 8 or 9

(must be used if $N(16)=1$ or

$\operatorname{SCALX} \neq 0$ or 1 ).

(31-40) DLABY $=$ same as DLABX except for $\mathrm{Y}$ label.

(41-50) EXTR $=$ the number of data point pairs to be read in card set $10.0 \leq$ EXTR $\leq 90$.

Note: All should be zero if $\mathrm{N}(2)=-1,-2$.

Card set $8 \quad$ Present only if $N(16)=0$. There are $\mathrm{N}(13)$ sets of these cards. $I=1, N(13)$.

\section{Card 8.1}

Format (2I10, 6E10.3)

$(1-10)$

ICY $(I)=$ tape record number to start plotting with dump frequency ICYD(I).

Not used if $N(4)=1$.

(I1-20) ICYD(I) = tape record frequency for plots between record ICY (I) and ICY $(I+1)$.

Not used if $\mathrm{N}(4)=1$.

(21-30) $T M(I)=$ time to start plotting at time intervals of TMD (I). Not used if $N(4)=0$.

(31-40) TMD $(I)=$ time interval for plots between time $\mathrm{TM}(\mathrm{I})$ and $\mathrm{TM}(\mathrm{I}+\mathrm{I})$.

Not used if $N(4)=0$.

(41-50) $\operatorname{XMIN}(I)=$ smallest $\mathrm{X}$ value to be plotted in this interval.

(51-60) $\operatorname{XMAX}(I)=$ largest $X$ value to be plotted in this interval.

(61-70) YMIN $(T)=$ same as $X M I N(I)$ except for $Y$.

(71-80) $\operatorname{YMAX}(I)=$ same as $X M A X(I)$ except for $Y$. 
Notes: Points outside of minimum-maximum range

are dropped. Tf $\mathrm{N}(13)>1$, plotting

will start at first record $\geq \operatorname{ICY}(1)$

and stop when record number > ICY (N(13))

if $\mathrm{N}(4)=0$ or start at first time

$\geq \mathrm{TM}(1)$ and stop when time $>\mathrm{TM}(\mathrm{N}(13))$

if $\mathrm{N}(4)=1$. In the case that

$\mathrm{N}(13)=1$, the program will plot until the tape end of file.

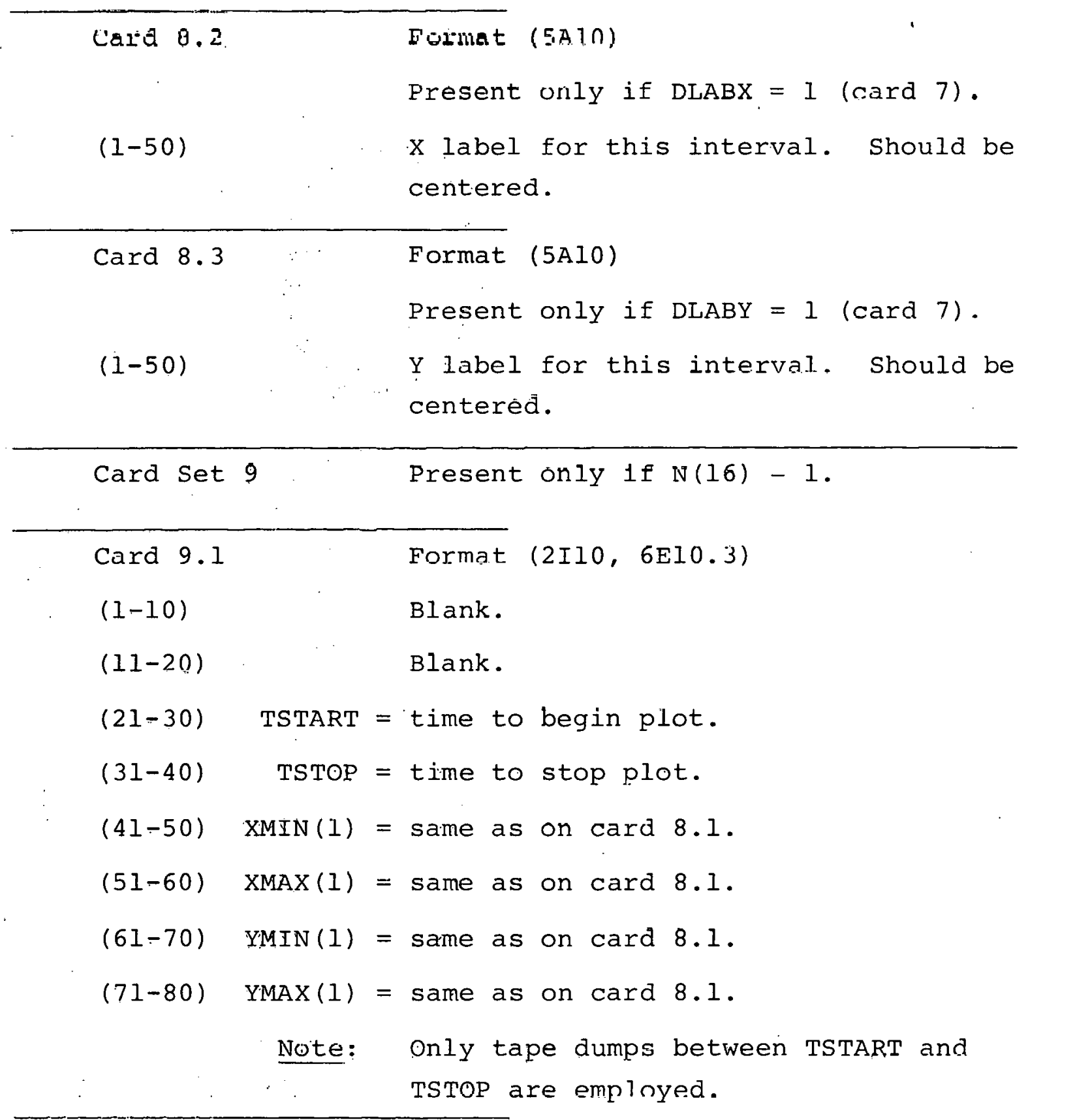


Card 9.2

Same as 8.2 (must be present).

\begin{tabular}{ll} 
Card 9.3 & Same as 8.3 (must be present). \\
\hline Card Set 10 & Format (2El0.3) \\
& Present only if EXTR $>0$ (card 7 ). \\
& There are EXTR sets of the following \\
& variables. \\
& I $=1$, EXTR \\
& EXTRX(I) \\
& EXTRY(I) \\
& This set of variables is plotted on \\
& each frame with lines connecting the \\
& points.
\end{tabular}

\begin{tabular}{|c|c|}
\hline Card 11 & $\begin{array}{l}\text { Format ( } 8 A 10) \\
\text { Present only if } N(16)=1 . \\
\text { Top label for graph. Only } 1-50 \text { are } \\
\text { used for small size frame. }\end{array}$ \\
\hline Card 12 & $\begin{array}{l}\text { Format (4I5) } \\
\text { Present only if } \mathrm{N}(2)=-1,-2 \text {. }\end{array}$ \\
\hline$(1-5)$ & $\begin{array}{l}\text { MULI'(1) Y variable code for } \\
\text { lst curve. }\end{array}$ \\
\hline$(6-10)$ & $\begin{array}{l}\text { MULT(2) Y variable code for } \\
\text { 2nd curve. }\end{array}$ \\
\hline$(11-15)$ & $\begin{array}{l}\text { MULT(3) Y variable code for } \\
\text { 3rd curve. }\end{array}$ \\
\hline$(16-20)$ & $\begin{aligned} \operatorname{MULT}(4) & \text { Y variable code for } \\
& 4 \text { th curve. }\end{aligned}$ \\
\hline & $\begin{array}{l}\text { For only } 3 \text { curves per frame, } \\
\operatorname{MULT}(4)=0\end{array}$ \\
\hline
\end{tabular}


For only 2 curves per frame,

$\operatorname{MULT}(4)=\operatorname{MULT}(3)=0$.

For only 1 curve per frame,

$\operatorname{MULT}(4)=\operatorname{MULT}(3)=\operatorname{MULT}(2)=0$.

If more plots are desired, go back to card 1 .

If finished, insert a blank card to stop. 


\section{REFERENCES}

[1] S. L. Thompson, H. S. Lauson, "Improvements in the Chart D Radiation-Hydrodynamic Code II: A Revised Program," Sandia National Laboratories Report SC-RR-71 0713, Albuquerque, NM, February 1972 .

[2] S. L. Thompson, "Improvements in the Chart D Energy Flow-. Hydrodynamics Code V: 1972/1973 Modifications," Sandia National Laboratories Report SLA-73-0477, Albuquerque, NM, October 1973.

[3] S. L. 'Ihompson, H. S. Lauson, "Improvements in the Chart D Radiation-Hydrodynamic Code III: Revised Analytic Equations of State," Sandia National Laboratories Report SC-RR-71 0714, March 1972.

[4] S. L. Thompson, "CSQ II - An Eulerian Finite Difference Program for Two-Dimensional Material Response--Part 1. Material Sections," Sandia National Laboratories Report SAND-77-1339, January 1979.

[5] I. Nelson, M. L. Baron, I. Sandler, "Mathematical Models for Geological Materials for Wave-Propagation Studies," in Shock Waves and the Mechanical Properties of Solids, J. J. Burke and V. Weiss, editors, Syracuse University Press, Syracuse, NY (1971).

[6] J. Lysmer, R. L. Kuhlemeyer, "Finite Dynamic Model for Infinite Media," ASCE, Engineering Mechanics Division, pp. 859-877, August 1969. 


\section{REFERENCES (Cont'd)}

[7] B. M. Dobratz; "LINL Explosives Handbook Properties of Chemical Explosives and Explosive Simulants," UCRL-52997, Lawrence Livermore Laboratories Report, Livermore, CA, March 1981 . 
Distribution:

R. M. Schmidt

Boeing Company

Aerospace Group

Shock Physics Laboratory

P. O. Box 3999

Seattle, WA 98124

D. L. Orphal

California Research \& Technology

6269 Variel Avenue, Suite 200

Woodland Hills, CA 91367

Commanding officer

Air Force Weapons Laboratory

Kirtland Air Force Base, NM 87117

Attn: Technical Library

Attn: L. Libersky

Commanding officer

Ballistic Research Laboratories

Aberdeen Proving Ground, MD 21005

Attn: Technical Library

Attn: J.J. Misey

Professor G. Duvall

Washington State University

Department of Physics

Pullman, WA 99163

Dan Vavrick

Honeywell, Inc.

600 Second street $\mathrm{NE}$

Hopkins, MN 55343

Kaman Sciences Corporation

P. O. Box 7463

Colorado Springs, CO 90933

Attn: J. May

Attn: T. Cook

H. A. Sabbagh

Naval Weapons Support Center

Code 7056

Crane, IN 47522

D. J. Chang

The Aerospace Corporation

P. O. Box 92957

Los Angeles, CA 90009

F. A. Stecher

Naval Surface Weapons Center

Code K-22, Reentry systems Branch

Dahlgren, VA 22448
J. L. Carter

Division of Project Management Advanced Reactors Branch

Room 268

Washington, DC 20555

M. Anthony

Oak Ridge National Laboratory

P. O. BoX X

Oak Ridge, TN 37830

Y. Horie

Department of the Army

P. O. Box 1211

Research Triangle Park, NC

M. Lutzky

Naval Surface Weapons Center

Building 323, Room 209

White Oak

Silver Spring, MD 20910

Pacifica Technology

P. O. Box 148

Del Mar, CA 92014

Attn: R. J. Bjork

Attn: J. Zerkle

Systems, Science \& Software

P. O. Box 1620

Lajolla, CA 92037

Attn: Technical Library

W. Smith

Vought Corporation

P. O. Box 225907

Dallas, TX 75265

Los Alamos National Laboratory

P. O. Box 1663

Los Alamos, NM 87545

Attn: Reports Library

University of California

Lawrence Livermore National Laboratory

P. O. Box 808

Livermore, CA 94550

Attn: Reports Library

Attn: G. R. Gathers (L-355)

Attil: D. W. Hanner (L-122)

Attn: M. L. Wilkins (L-355) 


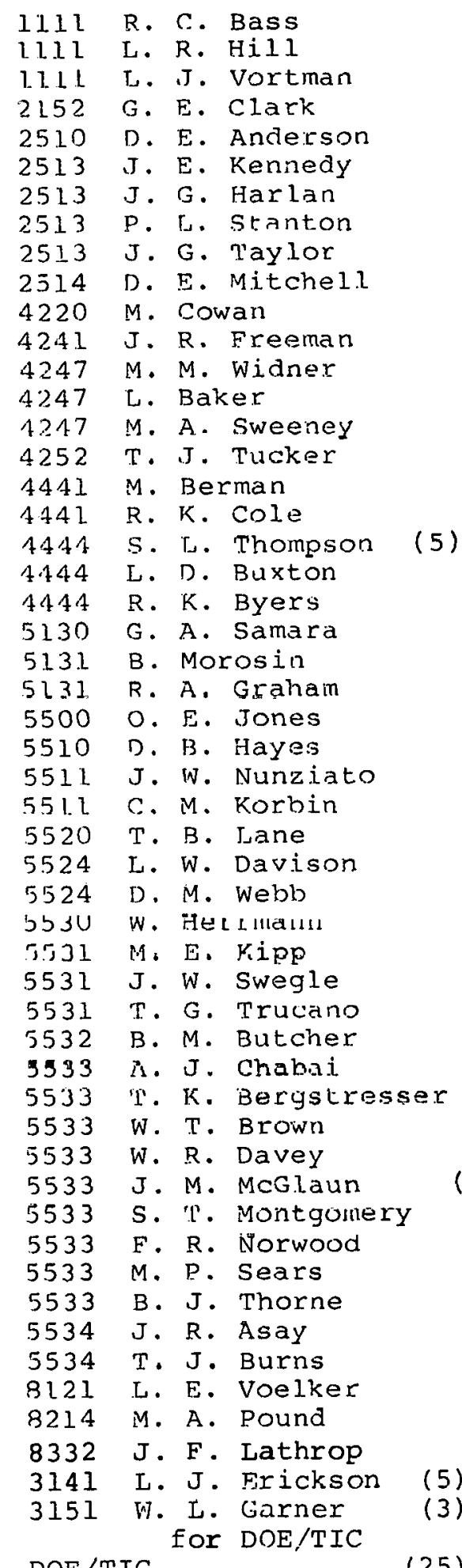

3] 54-4 J. Hernandez 


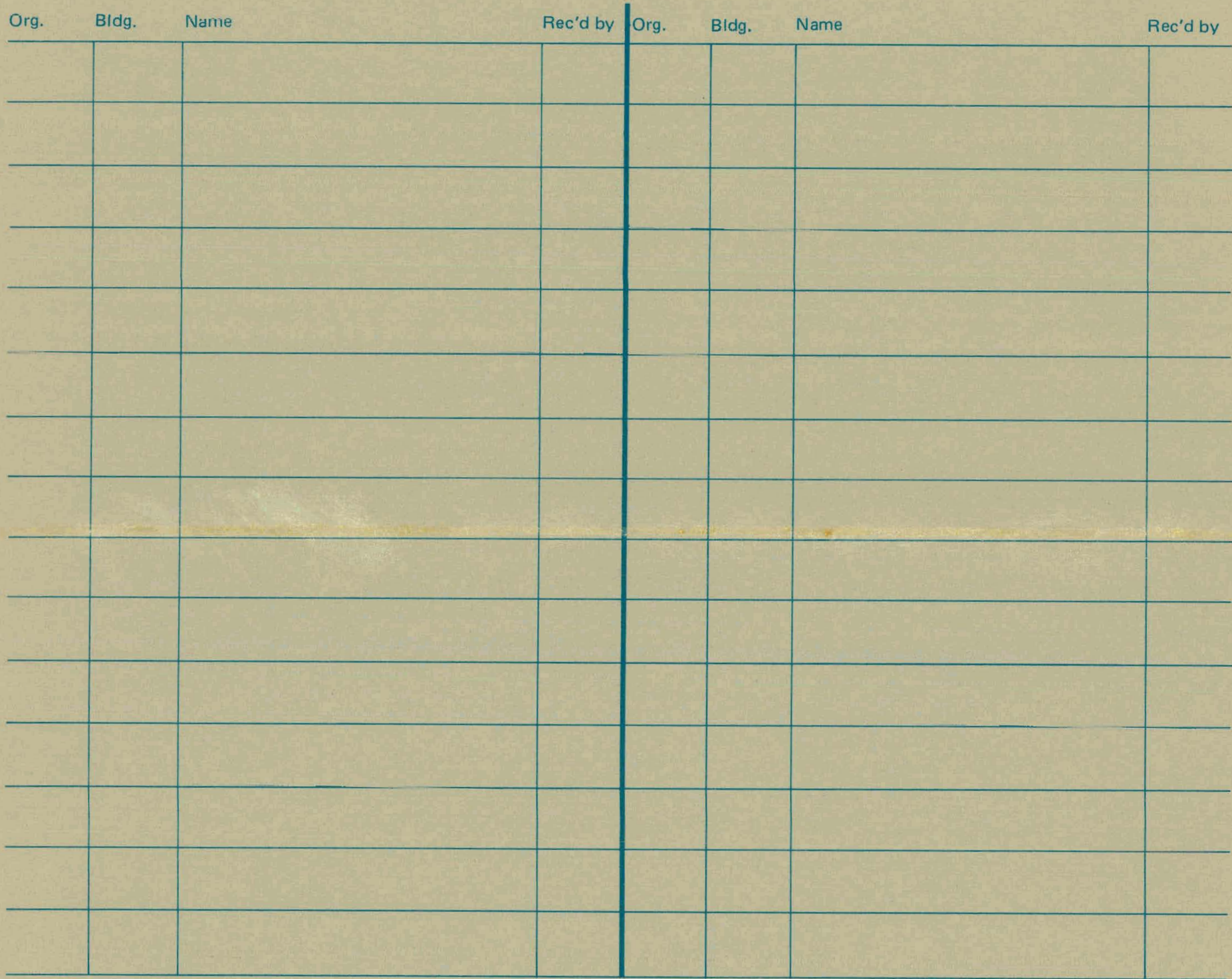

